\title{
Analysis of Fragmentation and Resulting Shrapnel Penetration of Naturally Fragmenting Cylindrical Bombs
}

S.E. Gardner

\section{August 1, 2000}




\section{DISCLAIMER}

This document was prepared as an account of work sponsored by an agency of the United States Government. Neither the United States Government nor the University of California nor any of their employees, makes any warranty, express or implied, or assumes any legal liability or responsibility for the accuracy, completeness, or usefulness of any information, apparatus, product, or process disclosed, or represents that its use would not infringe privately owned rights. Reference herein to any specific commercial product, process, or service by trade name, trademark, manufacturer, or otherwise, does not necessarily constitute or imply its endorsement, recommendation, or favoring by the United States Government or the University of California. The views and opinions of authors expressed herein do not necessarily state or reflect those of the United States Government or the University of California, and shall not be used for advertising or product endorsement purposes.

Work performed under the auspices of the U. S. Department of Energy by the University of California Lawrence Livermore National Laboratory under Contract W-7405-Eng-48.

This report has been reproduced directly from the best available copy.

Available to DOE and DOE contractors from the Office of Scientific and Technical Information

P.O. Box 62, Oak Ridge, TN 37831

Prices available from (423) 576-8401

http://apollo.osti.gov/bridge/

Available to the public from the National Techunical Information Service

U.S. Department of Commerce 5285 Port Royal Rd., Springfield, VA 22161

http://www.ntis.gov/

\section{OR}

Lawrence Live:more National Laboratory Technical Information Department's Digital Library http://www.llnl.gov/tid/Library.html 


\title{
Analysis of Fragmentation and Resulting Shrapnel Penetration of Naturally Fragmenting Cylindrical Bombs
}

\author{
S. E. Gardner \\ Summer Student \\ Department of Mechanical Engineering \\ Brigham Young University
}

August 2000

Lawrence Livermore National Laboratory University of California, Livermore, California 94550 


\section{TABLE OF CONTENTS}

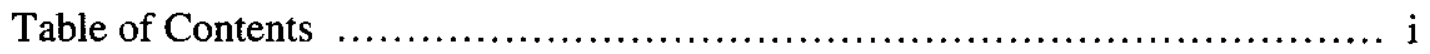

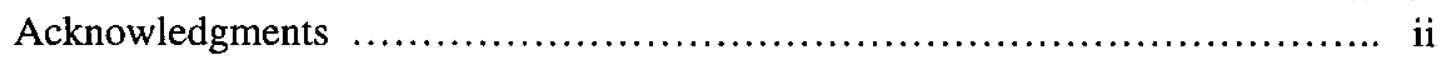

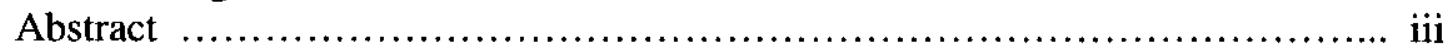

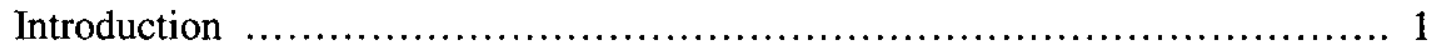

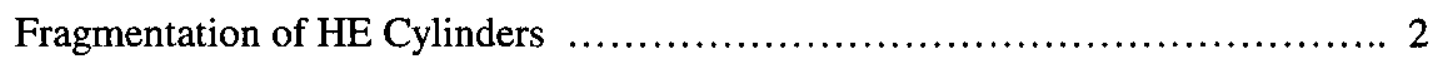

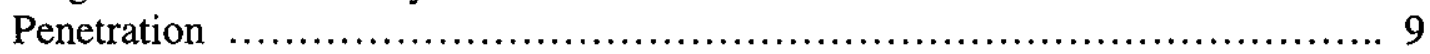

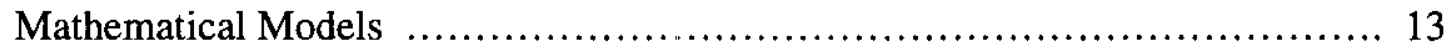

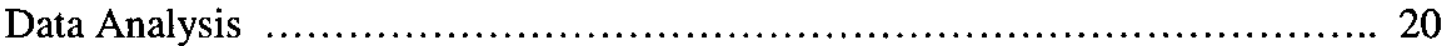

Conclusions and Recommendations

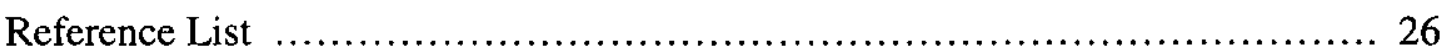

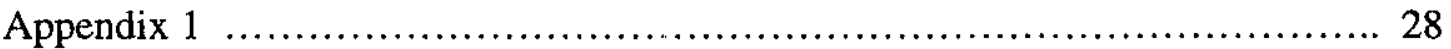

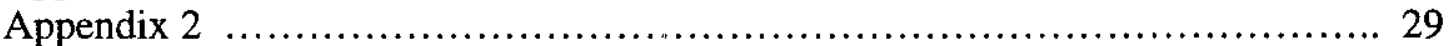

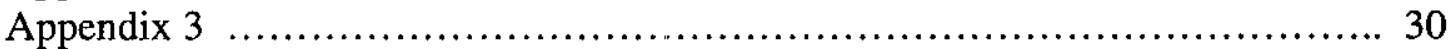




\section{Acknowledgments}

The author would like to thank John Pastrnak and Carl Henning for their help and guidance with this research and analysis. Thanks also go to Rocco Hollaway, Chuck Cook and Frank Gensheer for their help in locating and acquiring the LANL h-2223 witness plate.

Work performed under the auspices of the U.S. Department of Energy by the University of California Lawrence Livermore National Laboratory under Contract W-7405-Eng-48. 


\begin{abstract}
Fragmentation of exploding cylinders and penetration mechanics of surrounding vessel walls were examined and a qualitative understanding was achieved. This understanding provided a basis for making simplifying approximations and assumptions that aided in creating a shrapnel penetration model. Several mathematical models were discussed, and results from 6 cylinder tests were analyzed in order to select a model that best represented the data. It was determined that the overall best mathematical model to predict shrapnel penetration uses the modified Gurney equation to calculate fragment velocity, the Mott equation to calculate largest fragment weight, and the Christman/Gehring equation to calculate penetration depth.
\end{abstract}




\section{Analysis of Fragmentation and Resulting Shrapnel Penetration of Naturally Fragmenting Cylindrical Bombs}

\section{Introduction}

In order to observe and analyze the dynamics of high-explosive (HE) experiments, it is sometimes important to contain them. This is to protect diagnostic equipment from damage and the environment from potentially toxic debris. The use of containment/firing vessels is one way of providing protection. In preparation for designing and constructing experimental firing vessels, a reliable methodology must be devised to predict the shrapnel effects of the metal explosives casing on the containment vessel wall. In particular, it is important to find or develop formulas that accurately predict the penetration depths of the shrapnel into the walls of the surrounding containment vessel. Extensive research has already been conducted in the field of penetration mechanics, and a number of penetration equations exist. However, in order to select penetration equations that are appropriate to the circumstances envisioned here, it is necessary to first gain a firstprinciples understanding in both fragmentation and penetration mechanics. Fragmentation of HEfilled metal cylinders are examined first in order to understand the mode(s) of failure of an explosively expanding right cylinder and to predict fragment size and velocity distributions. The effect of fragment orientation at impact is also examined. Penetration models and their respective equations and limits of validity are then reviewed. The overall objective of this study is to determine a method for accurately predicting the penetration depth of shrapnel from cylindrically encased high explosive experiments (pipe bombs).

The aforementioned contained firing vessel is to be designed for the experimentation of cylindrically encased high explosives (see figure 1). Typical casing materials are steel or copper. To generate worst-case shrapnel, the cylinders are to be detonated from both ends such that the detonation waves meet at the cylinder's middle. The tests will be conducted inside a spherically shaped aluminum containment vessel approximately 2 meters in diameter (see figure 2), which will be over-wrapped with Kevlar fiber for strength against blast pressures. Various explosives will be tested in varying amounts. The casings will also be of varying size, thickness, and material type. Fragmentation and penetration models need to be able handle these different conditions. Only effects due to shrapnel penetration will be considered here.

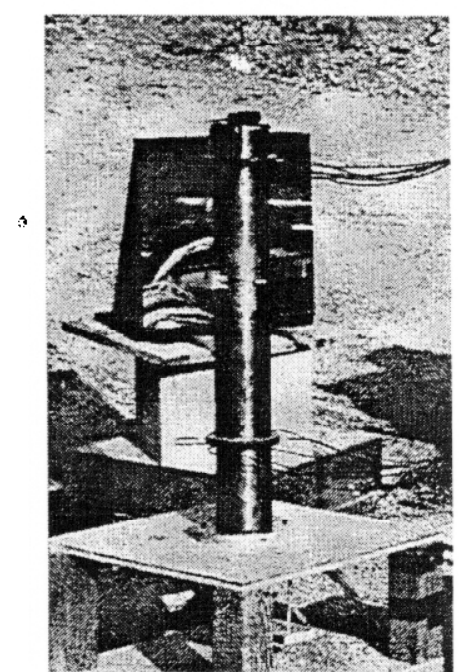

Figure 1. Typical test cylinder. [1]

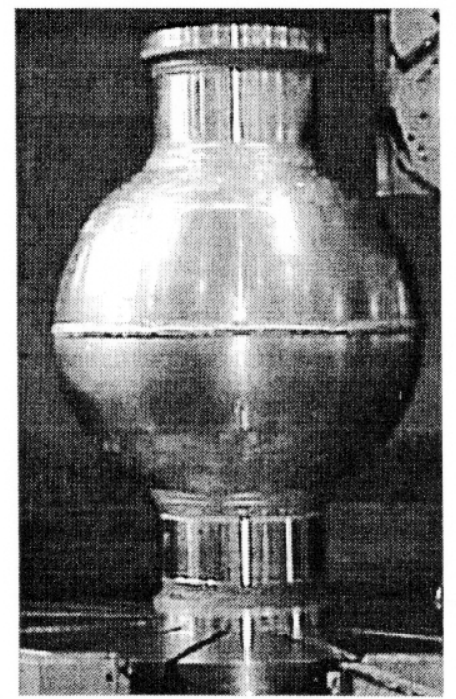

Figure 2. Aluminum liner of protot composite firing vessel. 
It is by no means a small challenge to find a method of analysis for exploding cylinders. As previously stated, there is a large volume of reference material relative to the subject. A significant obstacle is that nearly every study done has been very specific. Consequently, the mathematical models that are derived are anything but comprehensive or omni-applicable. Most are only accurate for the specific conditions of a particular experiment. In order to develop a method of analysis applicable to a diverse range of exploding cylinder tests, parts from many separate studies and reports are necessarily pulled together. As a result, regimes of validity and compatibility become important issues. In addition, the exploding and fragmenting of a bomb is a very complicated phenomenon and any resulting model will be significantly idealized and simplified from reality.

\section{Fragmentation of $\mathrm{HE}$ Cylinders}

As previously stated, high performance firing vessels could be designed for the detonation of cylindrically encased high explosives. For this study, one primary concern is to determine what are the most damaging fragments that are produced by a typical cylinder test. Factors to consider are the mass, velocity, shape and orientation of the fragments as they strike their target. Since the test cylinders are detonated at both ends, it is assumed that the worst-case fragments will result from the central region where the detonation waves meet. In an artillery shell test conducted for LLNL [2], it was recorded that shrapnel from the midsection of the shell casing detonated at one end had the greatest acceleration and velocity, supporting to a certain extent the assumption that the worst-case fragments originate from this portion of an exploding cylinder. Conversely, many references state that fragment number decreases (or fragment size increases) as strain rate and detonation pressure decrease. Since the superposition of two detonation waves would increase the local strain rate and detonation pressure, fragment size would be expected to decrease. The high strain rate is analogous of a brittle fracture, resulting in many smaller fragments. The presence of worst-case fragments originating from the center portion, whether due to size or velocity or both, is yet to be determined.

An appropriate fragmentation model consists of many elements. In general, the fragmentation process can be broken down into four steps and shown in figure 3 below [3]. First, the case expands due to very high internal pressure that accelerates the case wall outward. Then after a very short time, on the order of about $10-50 \mu \mathrm{s}$, cracks begin to propagate through the case wall. Third, gas products begin to vent as cracks propagate completely through the cylinder wall. At this point, the cylinder wall has attained maximum velocity, since the expanding gases no longer accelerate it. Finally, fragments appear and the detonation cloud begins to decay. Each of these steps will be considered. Little attention will be given directly to the venting and decaying of the explosive gases other than in relation to fragment velocity. 


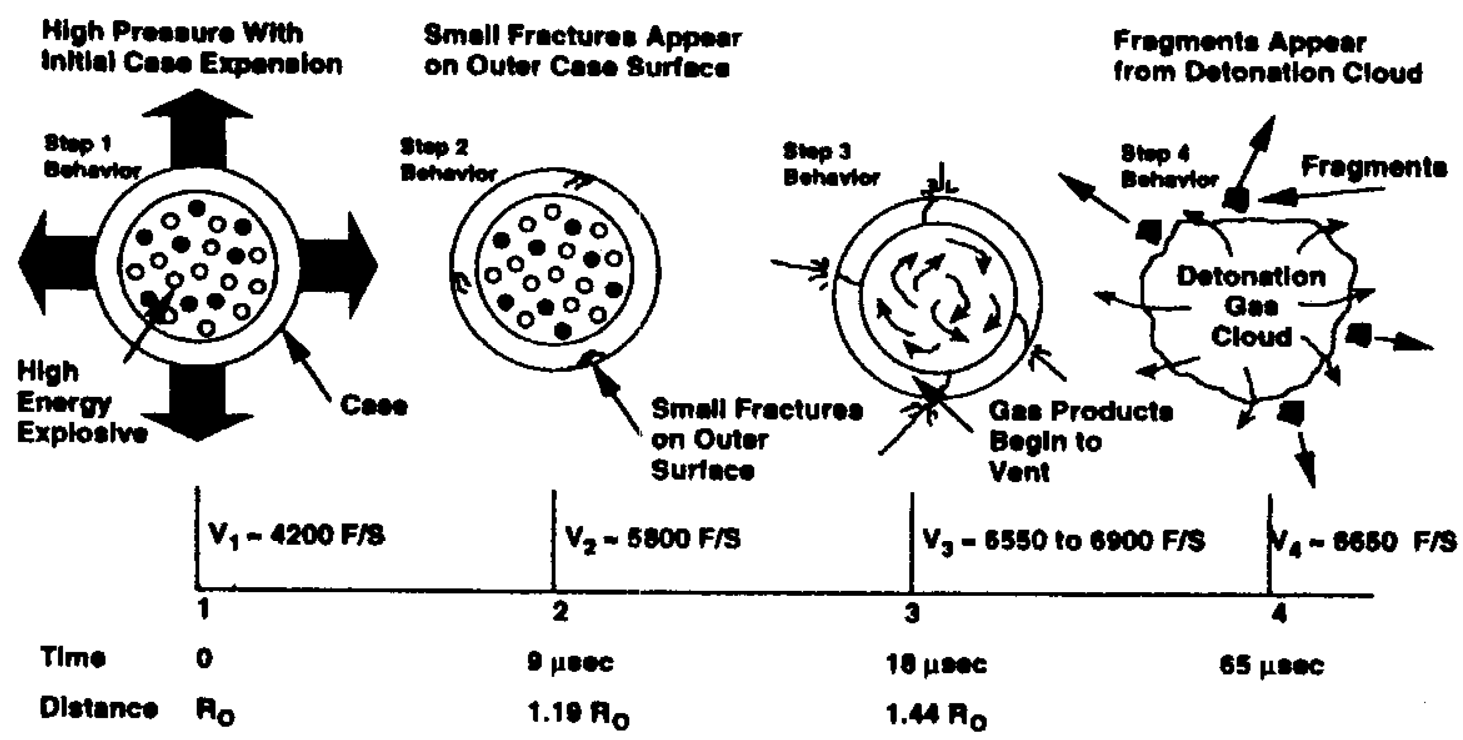

Figure 3. Fragmentation process [3 p. 21].

Case expansion prior to fracture is important for several reasons. First, The amount of energy actually transferred from the expanding gases to the cylinder largely depends on how long the case holds together before fragmenting. As the casing begins to fragment, the explosive gases are allowed to escape the containment of the cylinder without further transferring energy to the resulting fragments. For example, in a study done by G. I. Taylor in 1944, long cylindrical bombs were detonated from a single end [4]. It was determined that in order to transfer $50 \%$ of the explosive energy into the cylinder, it was necessary for the casing to hold together until its radius has increased by $90 \%$. Energy transfer is important because it determines the velocity of fragments. The exploding gases accelerate the cylinder wall as the case expands. At the point of fragmentation, this acceleration ceases because the gases are allowed to vent through the cracks without transferring any more of their energy. As a result, the maximum fragment velocity greatly depends on how far the case expands.

The extent to which a shell will expand depends upon several factors including loading conditions, thickness, softening, yield stress, strain rate, and the thermal properties of the material [5]. Shells made of materials such as copper that are more ductile often expand to about 2-2.4 times their original size before fragmenting, depending on the initial case thickness. Steel shells often expand to 1.2-1.5 times their original diameter, again depending on the initial case thickness. The expansion diameter is important to hypothesizing fragment size and thickness. Figure 4 shows typical expanding cylinders made of copper and steel. Mathematical treatment of both fragment velocity and size will be given later. 


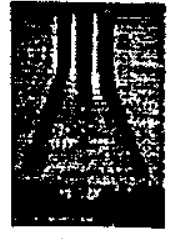

33.855

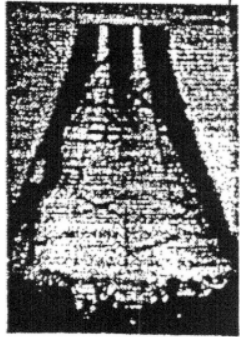

45.14

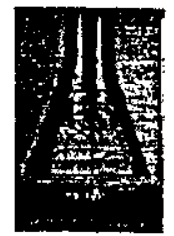

36.112

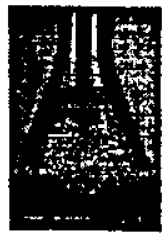

38.369

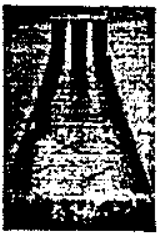

40.626

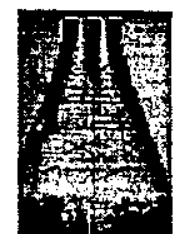

42.883

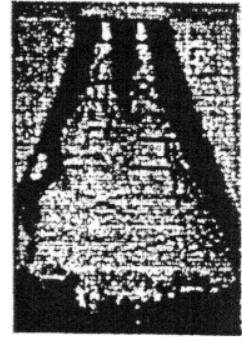

47.397

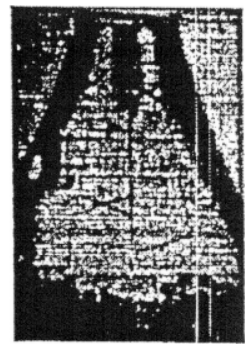

49.654

Figure 4. a) Expanding thin copper cylinder. Times are in microseconds. [11 p.75]
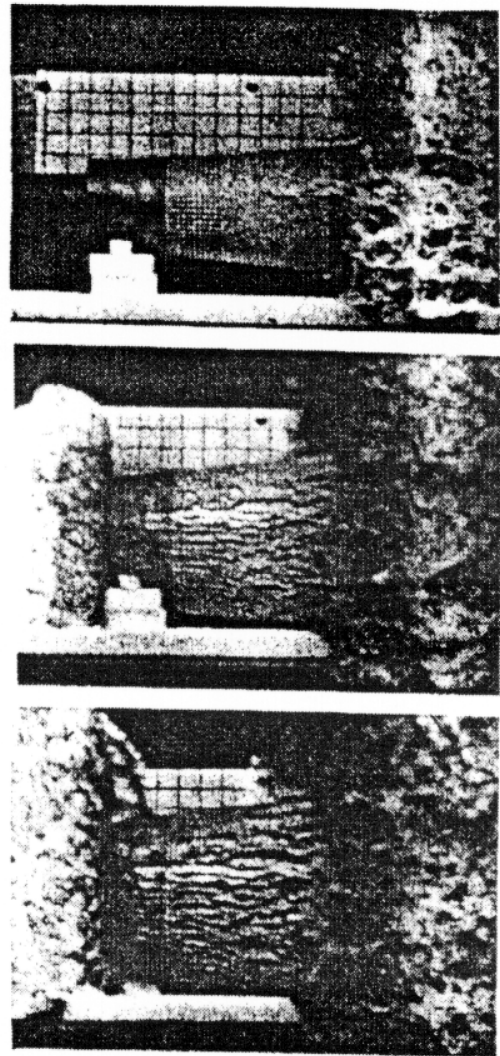

b) Expanding steel cylinder. [3 p.44]

After expanding, an exploding cylinder will break apart. It is important to understand the nature of this break up so that fragment sizes, shapes, and trajectories may be determined. Intuition and fracture mechanics lean toward to the idea that fragmentation of metallic cylinders is a twodimensional phenomenon [6,9]. That is, the cylinder case does not fracture within its thickness and fragment thickness is equal to the final, expanded case thickness. During WW II, Mott and Linfoot analyzed fragment mass distributions for warheads and bombs. Their results suggested that the larger fragments were characteristic of a two-dimensional fracture while the smaller fragments were more characteristic of a three-dimensional fracture [7]. Since the fragments of primary concem here are the larger ones, a two-dimensional fracture model is appropriate, and it can be assumed for large fragments that the front and back fragment surfaces correspond to the inner and outer casing surfaces. However, as previously stated, typical casings can expand to more than twice their original diameter, depending on the ductility and thickness of the material. As a result, fragments collected from cylinder tests commonly experience a $40-60 \%$ reduction in thickness from that of the original casing $[8,9]$.

According to Taylor and others, an explosively expanding cylinder experiences a combination of two modes of failure $[3,4,9,10]$. An exploding cylinder is initially in complete compression. As the casing expands, the cylinder wall is subjected to outer tensile and inner compressive hoop stresses. These stresses meet at a boundary within the thickness of the cylinder wall. The outside surface (in tension) develops radial cracks that propagate a short distance inward to the tensile/compressive stress boundary. As the radial cracks (due to tension) propagate inward, the stress boundary also 
moves inward through the cylinder wall (see figure 5). Thermal softening of the cylinder material outweighs work-hardening effects as the cylinder expands and causes the cracks to propagate along lines of maximum shear [9]. Consequently, the exploding cylinder fails due to a combination of tension and shearing $[6,8,9]$. This model explains the common appearance of both radial and shear fracture characteristics on recovered fragments.

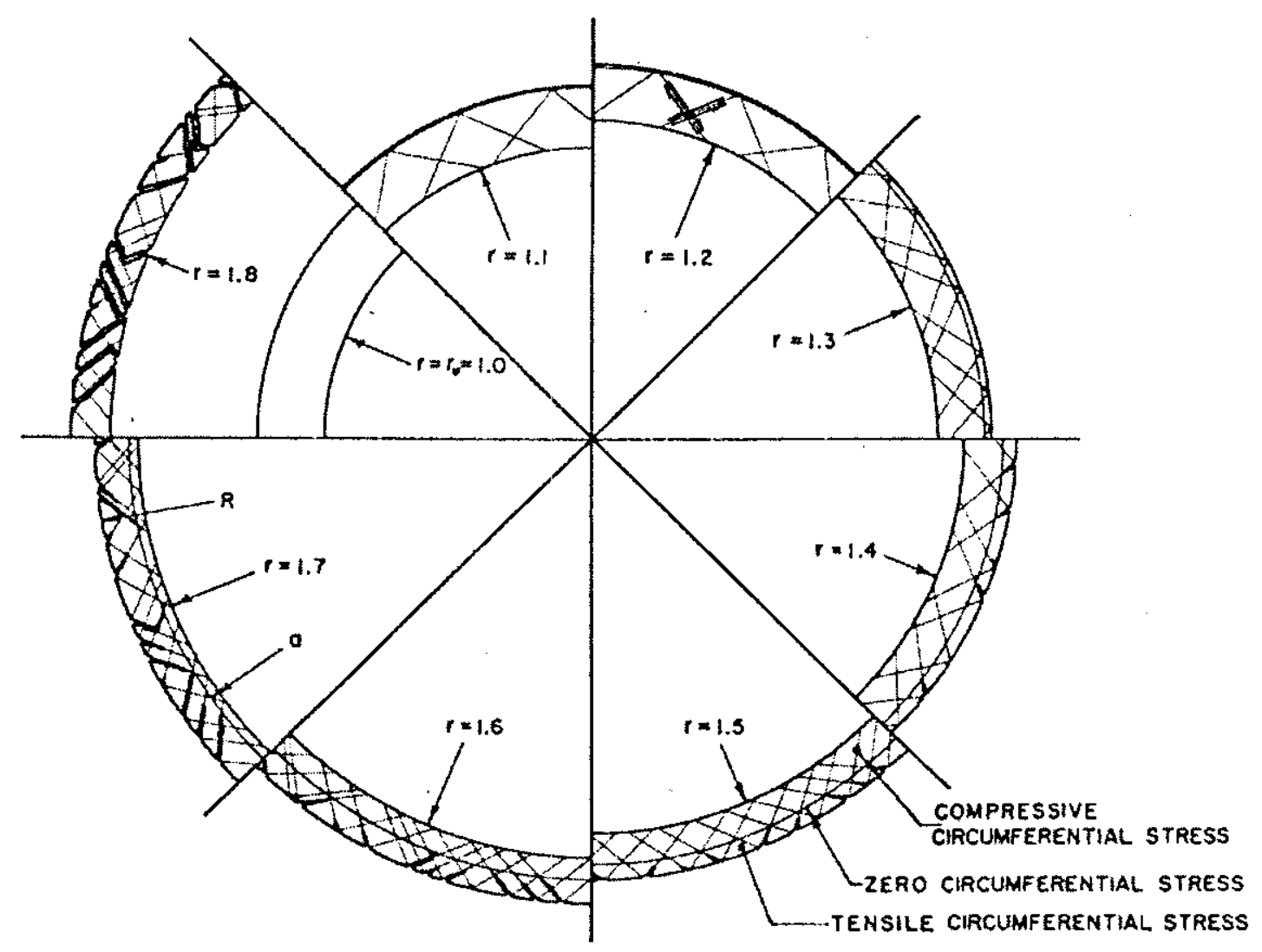

Figure 5. Fracture mechanisms during an explosively expanding cylinder. [9 p.1861]

Another model proposed by Martineau gives a slightly different explanation of wall failure [11]. His studies showed that multiple plastic instabilities develop on the inner and outer surfaces of a cylinder as it expands. His model suggests that the instabilities are caused by perturbations that initiate from within the cylinder wall. These perturbations are thought to be caused by the nucleation of micro voids along grain boundaries within the cylinder material. As the cylinder expands, the perturbations work their way to the inner and outer shell surfaces, giving rise to plastic instabilities. As mentioned previously, an explosively expanding cylinder is initially in complete compression, and as it expands, it becomes subjected to tensile stresses throughout its thickness. In contrast to the failure model described above, Martineau explained that once the shell reaches a condition of complete tension, the surface instabilities cause localized thinning of the shell wall, somewhat like necking (see figure 6). Then regions of intense shear connect the inner and outer surface instabilities, resulting in fracture (see figure 7). Observations from careful experimentation were in good agreement with this model. It was also noted that the instabilities propagate longitudinally along the axis of the cylinder, suggesting that typical cylinder fragments are elongated strips. 


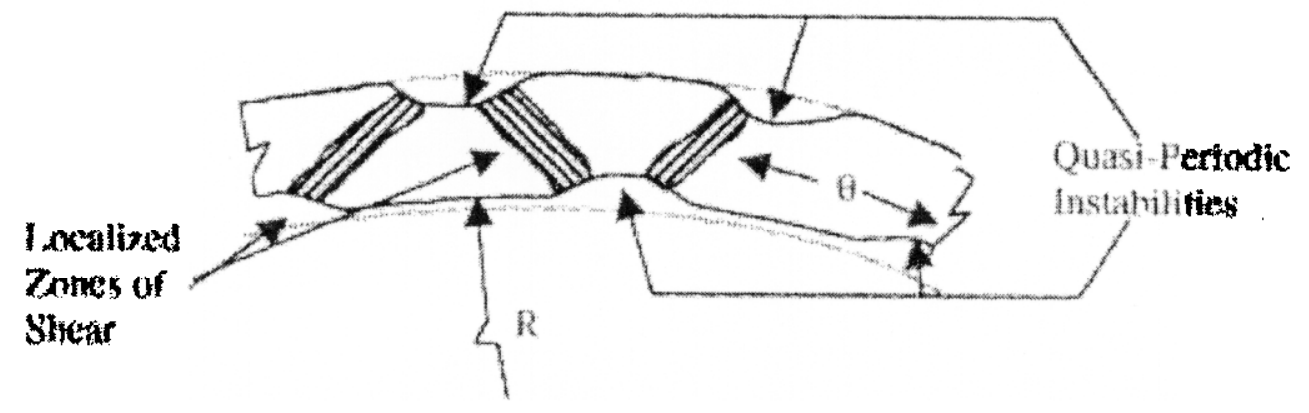

Figure 6. Localized thinning of cylinder wall caused by surface instabilities. [11 p. 97]

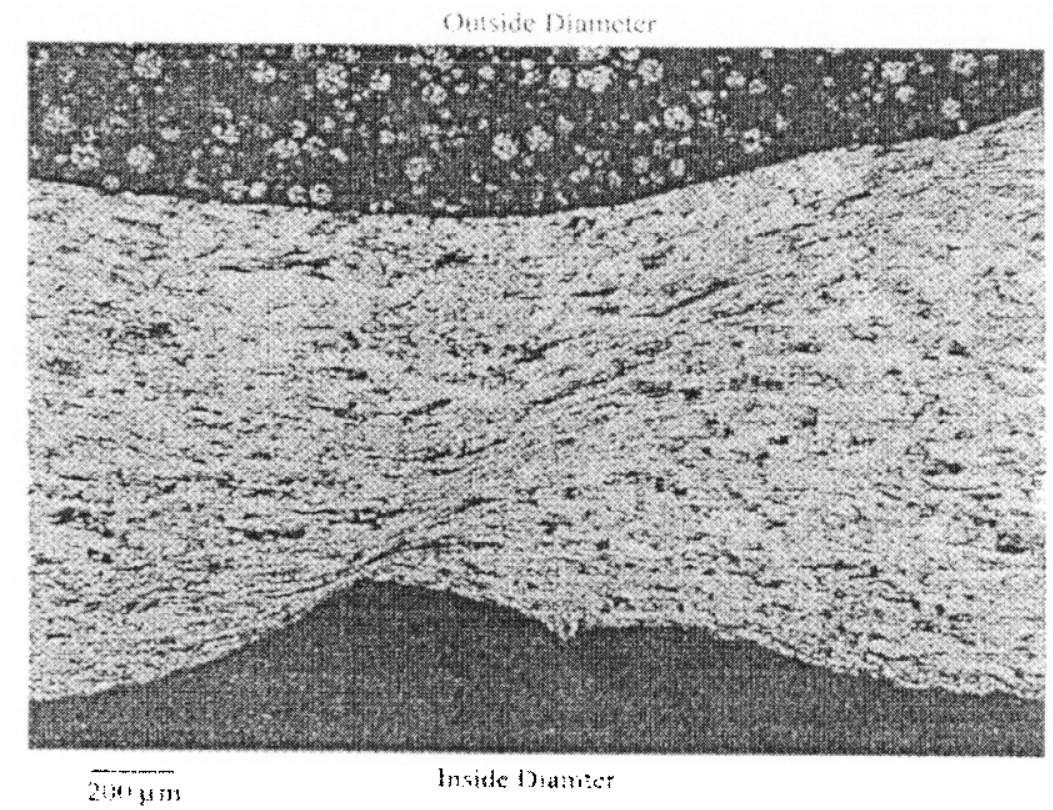

Figure 7. Photomicrograph of shear band between zones of localized thinning in an expanded cylinder wall. [11 p.97]

The apparent contrast in the two models described above may be resolved by recalling that Martineau's model and experiments dealt with strain rates on the order of $10^{4} \mathrm{~s}^{-1}$. Reference [3 p.45] describes a fracture model that is similar to that of Martineau as being characteristic of these higher strain rates. Consequently, both fracture models may be accurate, depending on the strain rate that is considered. Furthermore, reference [3] states that case thickness and ductility (which are also key factors in determining expansion diameter) affect whether shear or radial fracture is predominant. In any case, either model results in good predictions of fragment size.

Having discussed modes of failure, fragment size and shape will now be treated. Several models that predict fragment size and distribution will be briefly considered later. For the time being, a more qualitative discussion will be given. All of the models reviewed in this study share a common feature in their derivation. During expansion, there is a finite probability that fracture of the cylinder wall will occur as the stress level approaches a critical value. As soon as fracture occurs at one point, stress is relieved in the adjoining regions on either side of the fracture (see figure 8 below). These 
regions of unloading spread at a calculable velocity away from the crack and additional cracks cannot form within these unstressed areas. Consequently, there is a relationship between the rate at which cracks are nucleated and the unloading of the cylinder wall. This relationship determines average fragment width, which is a basis for predicting average fragment mass. Particulars of the different fragment size models are explained below.

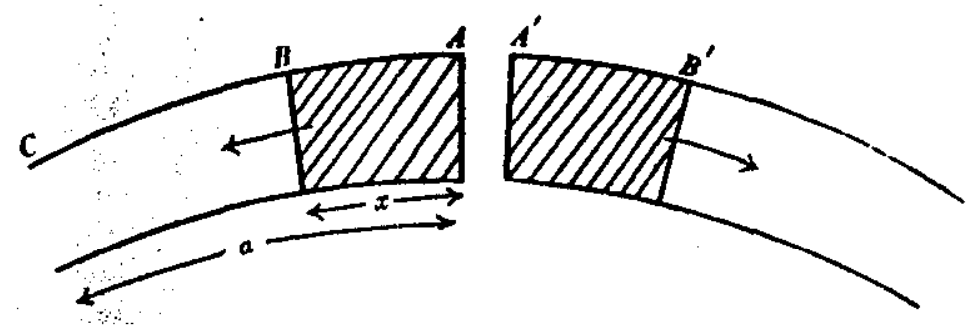

Figure 8. Unloading of stressed regions after fracture. [12]

Grady and Hightower have derived equations based on fragmentation energy to predict average circumferential fragment width for explosively expanding steel cylinders [6]. Their model will be discussed in more detail later. For now, it is interesting to note some of their results. Figure 9 gives the fragment size distribution for the experiment. Note the comparison of the average fragment width and the original case thickness. A large number of fragments were recovered from the experiment, and it was observed that fracture occurred predominantly along elongated strips with the lines fracture running parallel to the axis of the cylinder. Several of the fragments collected were 4 to 5 times longer than the width, suggesting the possibility of the formation long-rod penetrators.

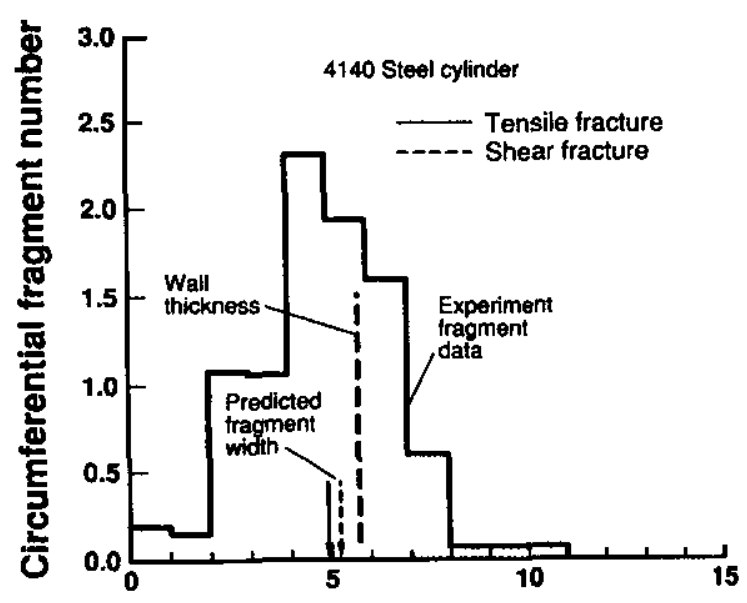

Circumferential fragment width $(\mathrm{mm})$

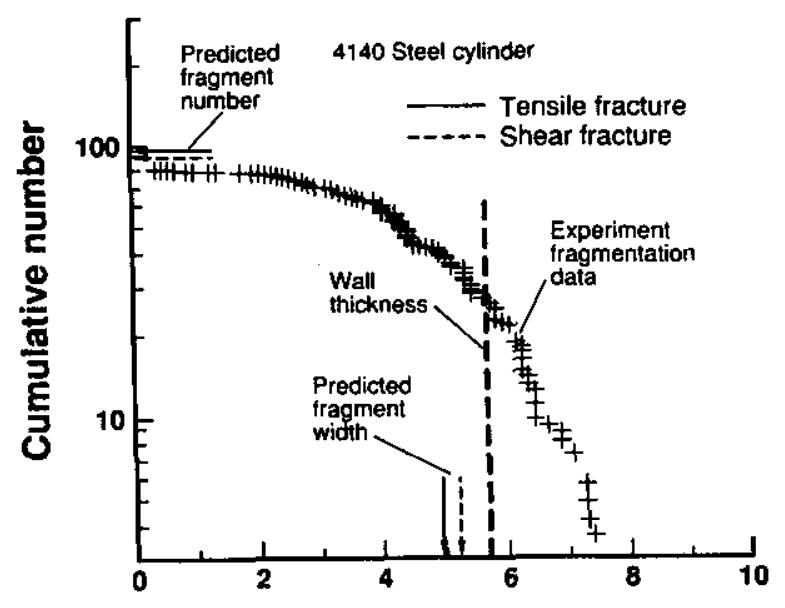

Circumferential fragment width $(\mathrm{mm})$

Figure 9. Predicted values from two different models are compared with experimental data [6]. One model was based on a tensile fracture failure mode and the other on shear fracture.

In general, the larger fragments from exploding cylinders are in the form of elongated strips $[3,9,12]$. As explained earlier, naturally fragmenting cylinders usually produce fragments that have come from longitudinal strips parallel to the axis of the cylinder. They will therefore be generally long and slender. Figure 10 below gives examples of typical cylinder fragments. 

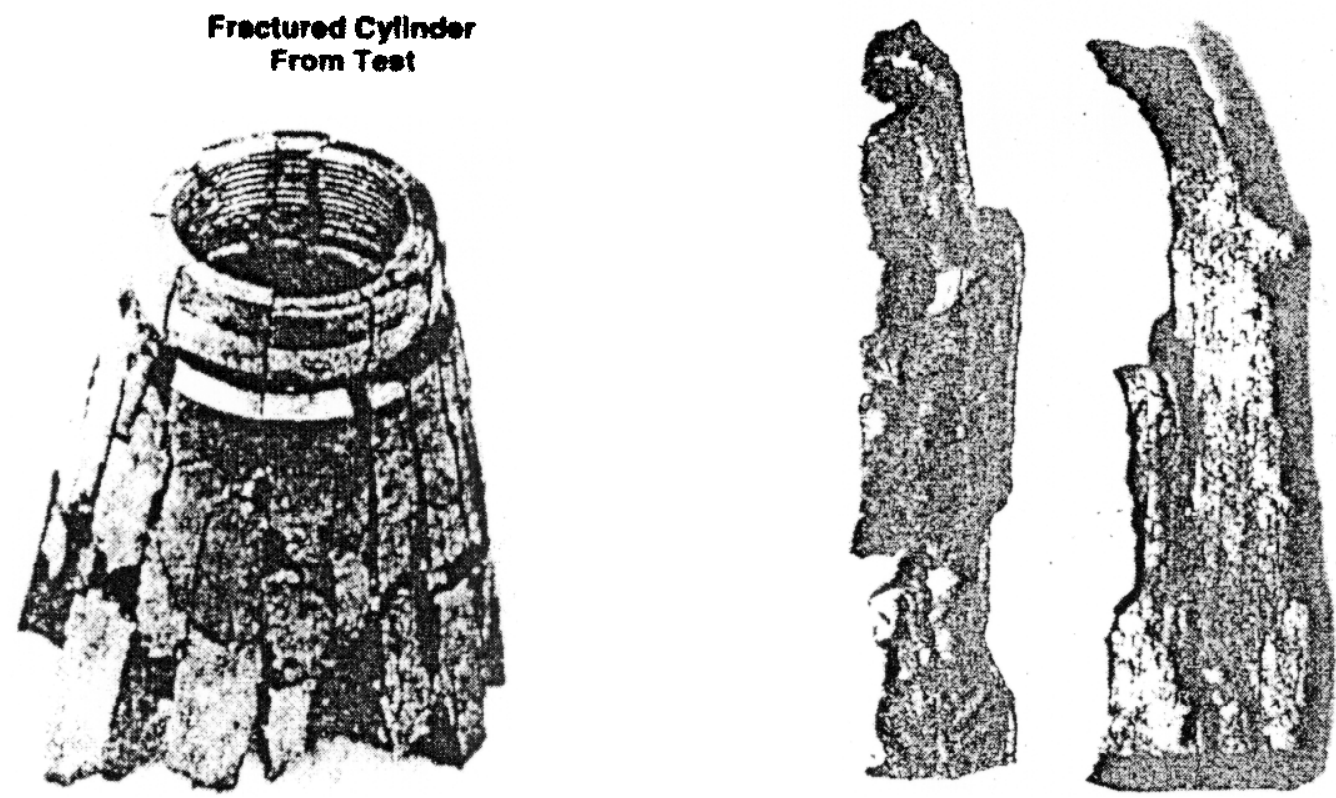

Figure 10. Typical elongated fragments from exploded cylinders $[3,9]$.

The Army has conducted several tests in which they have detonated and collected the fragments from warhead and bomb casings, which approximate exploding cylinders. Figure 11 comes form one such test and shows the sizes and shapes of typical fragments.

These long, finger-like projectiles can be very damaging if oriented normal to a target surface at the moment of impact, in which case they are termed long-rod penetrators. However, there is substantial evidence from observations of target craters that most of the shrapnel fragments produced in cylinder tests are more like "chunks" and less like "missiles" either in their dimensions or their net effect. In general, "chunky" fragments tend to form target craters that are roughly twice as wide as they are deep [16]. This makes good intuitive sense, and witness plates from various cylinder tests show that typical impact craters are of such dimensions [1,17]. Missile-type fragments would produce a deep crater with a relatively small opening. From figures 10 and 11 , it can be seen that the larger fragments that were recovered have the appearance of thick strips of bacon, elongated and wrinkled. If long-rod penetrators are in fact produced, it may be that they penetrate their targets at oblique or yawed angles, which would greatly reduce crater depths. Similarly, any angular velocity would also lessen their penetration potential. The "wrinkled" shape of the fragments would likely cause them to deform more easily upon impact, diminishing their effectiveness even more. It is probable that although many or most fragments are long and slender, the fact that they are very irregular in shape and trajectory would greatly reduce their penetration effectiveness, in which case they may behave as chunky fragments impacting simultaneously in parallel. In any case, there is not enough data to determine with certainty whether the elongated strip fragments are the most destructive fragments generated. Rather, impact damage seems more characteristic of chunky fragments. 


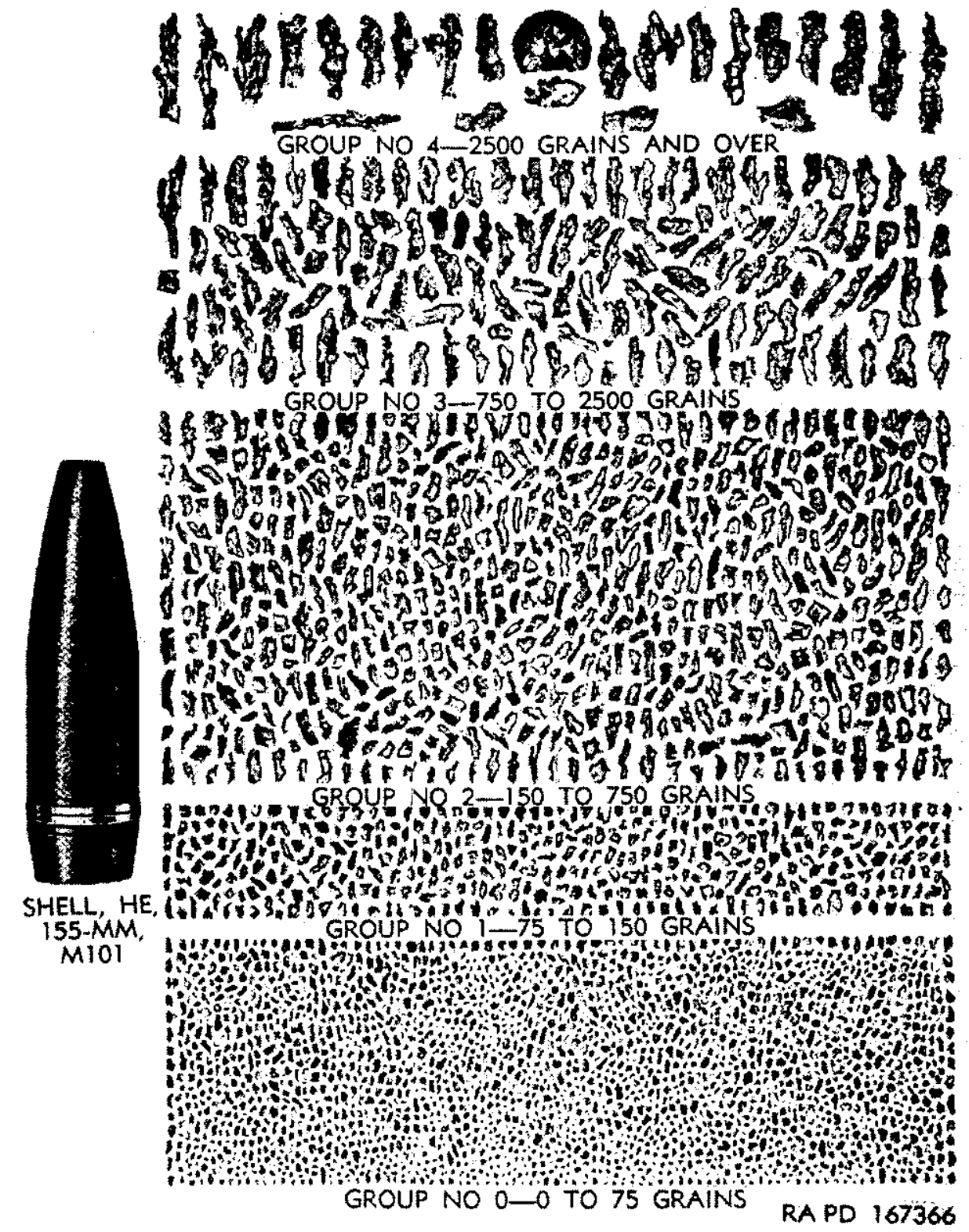

Figure 11. Results from Army fragment test [15].

\section{Penetration}

Models of penetration and perforation are based on laws of conservation and compatibility. As an explosion occurs, the chemical energy of the explosive reaction is imparted to the cylinder casing that encloses the HE. Some of the energy is used to deform and fracture the casing. Other energy is given off as light and heat. The remainder of the energy is imparted to the fragments as kinetic energy. Measuring or determining each of these energies is very difficult. For penetration and perforation analysis, the only important aspect is to predict the kinetic energy (i.e. mass and velocity) of the fragments. Once this kinetic energy is determined, conservation of mass and energy, sometimes in terms of momentum, is applied to the projectile/target system. The analysis is still quite complex because the events that occur at the projectile/ target interface are somewhat unknown. Although many studies have been performed, only highly controlled velocities, shapes, sizes and 
trajectories have been examined. As a result, numerous approximations and assumptions must be made in order to apply to these analyses to shrapnel fragments.

Impact is a very localized phenomenon. Stress and strain effects are usually limited to within 3-6 projectile diameters of the impacted zone [18]. Impacted target materials may fail by a combination of several modes including spalling, plugging, petaling, ductile or brittle fracture, and adiabatic shearing. Figure 12 shows some of these failure modes.
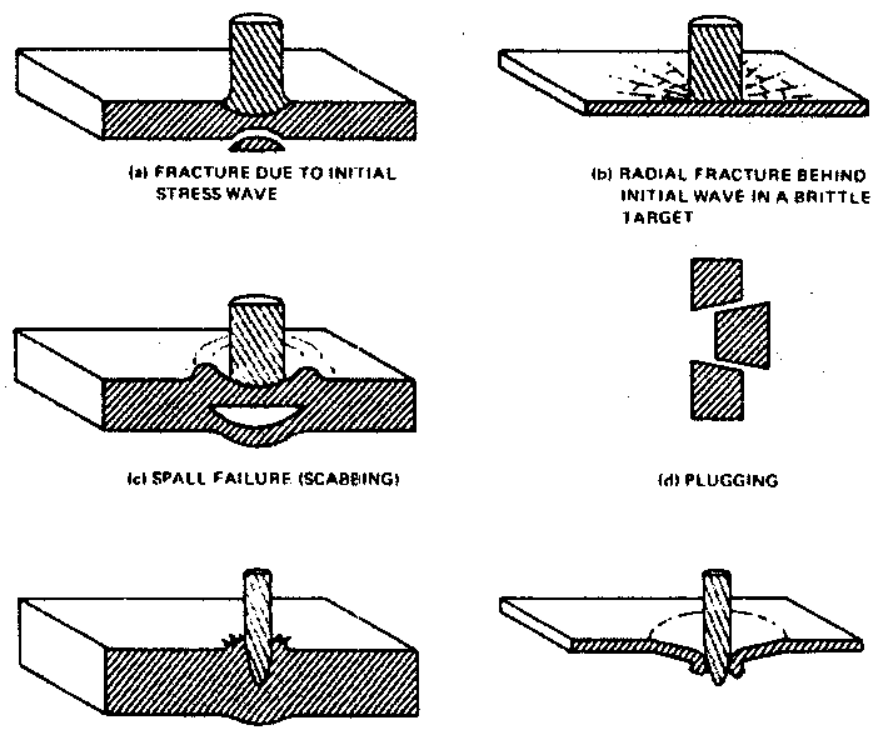

(e) PETALING IFRONTAL)
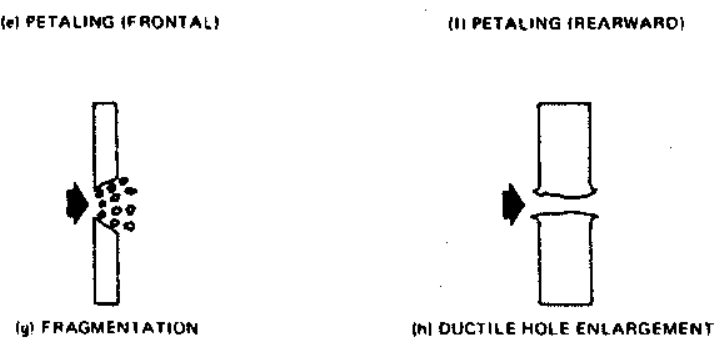

Figure 12. Common failure modes of impacted targets [33 p. 5].

In this study, only thick targets will be considered. A target is considered thick if the distal boundary is influential only after substantial travel of the projectile into the target. Thick witness plates of medium hardness, such as those for which we have data, seem to be characteristic of a combination of spalling and ductile failure [19]. Spalling is tensile failure of the target material due to the reflection of the initial compressive waves from the far side of the target [ 20 p. 523-546]. Failure by spalling can occur on either the front or back of a target and is characterized by the formation of petals or ejecta. In ductile failure, the impact impulse overcomes the peripheral dynamic shear strength of the target material, pushing it outward and toward the impact surface to form a crater that is much larger than the projectile diameter [21]. At the same time, the projectile pushes into the target, and there is hydrodynamic erosion and inversion of the penetrator material against the receding face of the target (see figure 13). 


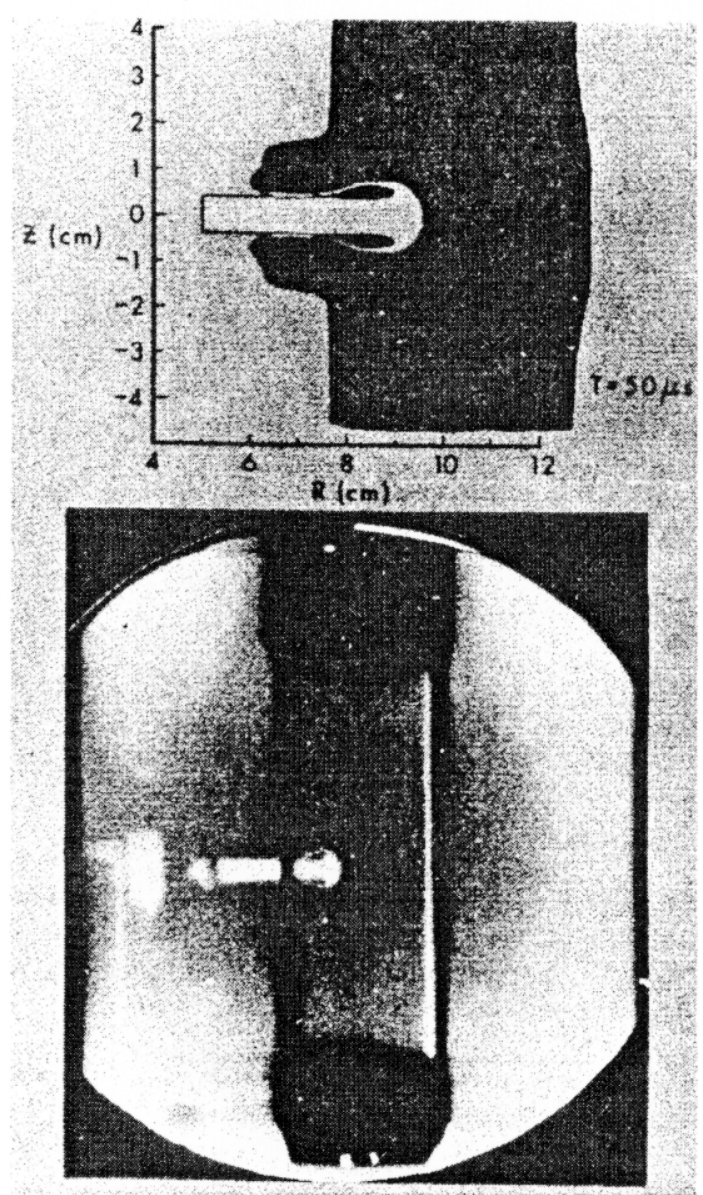

Figure 13. Ductile failure of a thick target and projectile erosion [19 p. 167].

The penetration process due to high-velocity impact can be represented by four phases: transient, primary penetration, secondary penetration, and recovery [32]. The first, or transient, phase is characterized by a very short pressure spike and occurs when the projectile first contacts the target surface. The primary penetration phase is described as the period during which the projectile acts as a contributing force, imparting its kinetic energy to the target in a hydrodynamic manner. The secondary phase (more than one phase may occur simultaneously), sometimes referred to as cavitation, begins after the projectile is completely deformed and effectively removed from the system as a source of energy. It is marked by target deformation not caused directly by the KE of the projectile material. Instead, the energy density behind the expanding shock wave continues to deform the target material. The fourth, or recovery, phase refers to the period during which the crater recovers or contracts slightly. Material just below the target surface anneals and recrystallizes.

With low-aspect ratio projectiles (chunky fragments), the primary phase is short and much less significant than the secondary phase. With high-aspect ratio projectiles, like long rods, the reverse is true because the majority of target deformation will come from the $\mathrm{KE}$ of the projectile. It will retain a penetrating surface for a longer time because there is more material to erode away as it penetrates into the target.

Projectile failure occurs simultaneously with target failure. Thus, penetration models involve both things. The projectiles deform and flatten/spread out as they strike the target, generating high 
resisting contact forces. As can be seen in figure 13 above, the projectile and target tend to form mating surfaces, which mushroom and erode the projectile as it moves through the target material $[19,22]$. Further support for this model is given in [23], in which it was studied whether a purely mushrooming or an eroding model more accurately described a projectile as it penetrated a target. It was determined that, at high velocities and high length-diameter (L/D) ratios, penetrator behavior predictions were bounded by the two models, suggesting that a combination of both phenomena actually takes place. For low L/D ratios, either model gave reasonable predictions. Expectedly, this also suggests that a combination of both phenomena actually takes place.

Another penetration model is similar to the erosion model, but of a more hydrodynamic nature. The particular treatment here is taken from [24]. In this model, the front end of the projectile and the impacted surface are modeled as flowing liquids. The regions directly behind these surfaces are then modeled as rigid bodies. The projectile is consumed from the impact end as it penetrates the target material and is transformed into a lining for the crater that it makes. This model requires a minimum velocity that is easily achievable in $\mathrm{HE}$ tests and predicts a crater diameter significantly larger than that of the fragment. Furthermore, it predicts that most of the impacted target material is displaced forward and outward by the projectile during penetration and that a small amount is ejected backwards.

An attempt will not be made at this point to determine which of the two models described above, if either, is more representative of shrapnel penetration. The models deal with very controlled geometries and circumstances. Numerous approximations and simplifications must be applied to shrapnel fragments in order to make these models more appropriate. They are presented here in order to get a general understanding of the penetration process. Observations of craters from one witness plate that was examined in this study seem to be compatible with either model (see figure 14).

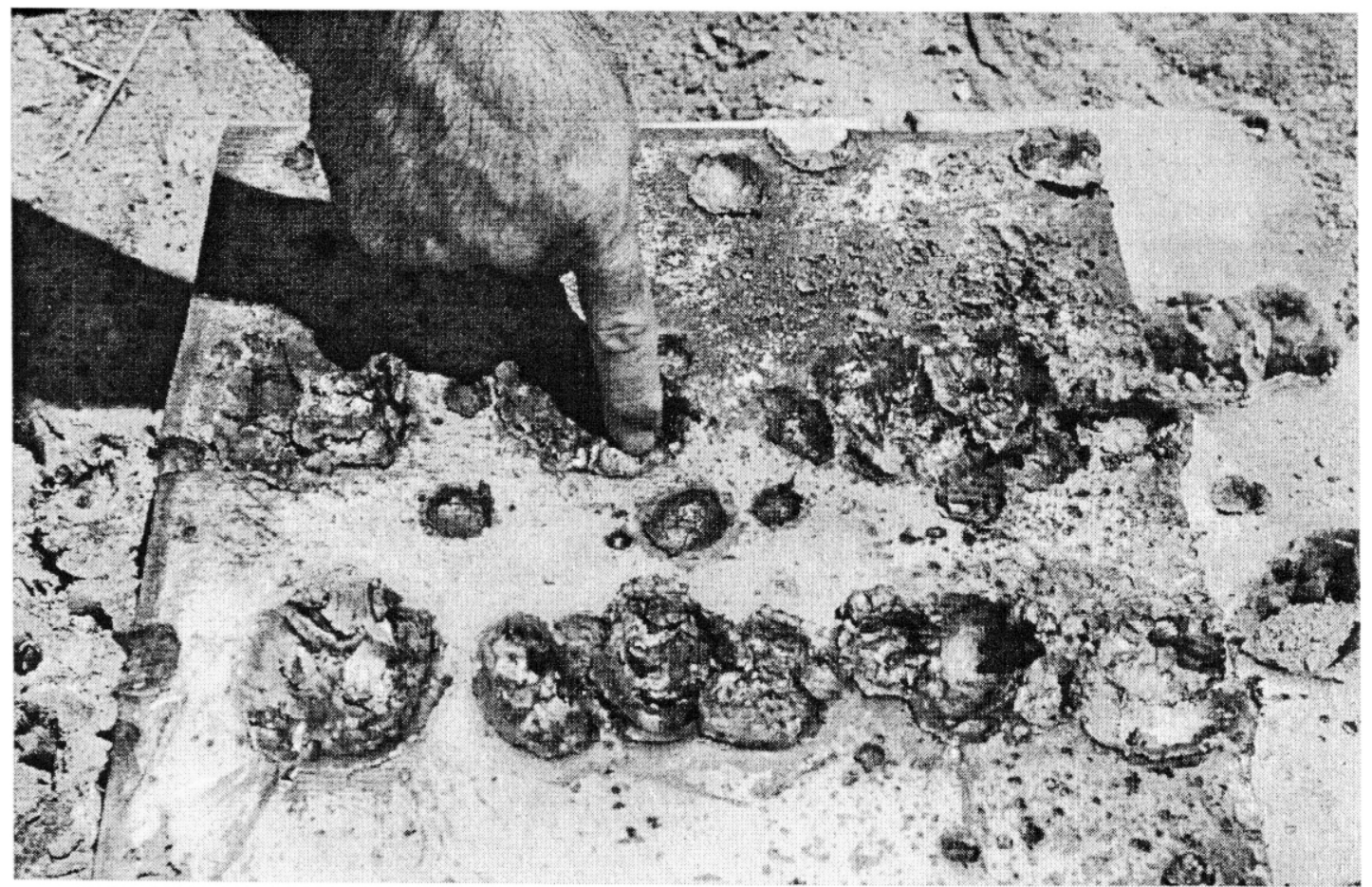

Figure 14. 2 in thick witness plate from a cylinder test conducted at LANL (shot no. H-2223). Crater dimensions are typical of cylinder tests. 
The ballistic limit is a common way to quantify projectile/target interactions. It is the minimum velocity required by a projectile in order to perforate a target. Several factors affecting ballistic limit [19], and in turn penetrability, include: target and projectile hardness, density and yield strength; projectile geometry, target thickness, striking yaw and obliquity. While all these factors are important, only the last two cannot be controlled. It is likely that shrapnel fragments will strike their targets at yawed or oblique angles. It is important to consider this, especially if long-rod penetrators exist among the shrapnel. In one set of experiments it was found that a yaw angle of approximately $10-15^{\circ}$ dramatically decreased the penetration depth of $\mathrm{L} / \mathrm{D}=11.7$ long-rod projectiles [25]. It appears that that angle may decrease slightly as the $\mathrm{L} / \mathrm{D}$ ratio of the penetrator decreases. Other sources have used $3-4^{\circ}$ as a critical yaw angle for increasing the required ballistic limit velocity [26]. This tends to support the hypothesis given earlier that if long-rod penetrators are produced from exploding cylinders, they may behave like "chunky" fragments.

\section{Mathematical Models}

Now that fragmentation and penetration mechanics have been examined at a first-principles level, it is appropriate to look at mathematical models that predict fragment size and velocity. A generally accepted equation for calculating average initial fragment velocity is the Gurney formula $[11,20 \mathrm{p}$. 234-242,27-31,34]. This simple formula, equation 1, is based on the assumption that the contribution to the total kinetic energy made by the detonation of a unit mass of explosive is independent of the size of the explosive casing. It also assumes that a certain portion of the chemical energy of the explosive is converted into fragment kinetic energy [30].

where

$$
\mathrm{V}_{\mathrm{o}}=\sqrt{2 \mathrm{E}} \sqrt{\frac{\frac{\mathrm{W}}{\mathrm{W}_{\mathrm{c}}}}{1+\frac{\mathrm{W}}{2 \mathrm{~W}_{\mathrm{c}}}}}
$$

$\mathrm{V}_{\mathrm{o}}$ is the initial velocity of the case fragment $(\mathrm{ft} / \mathrm{s})$

$\sqrt{2 \mathrm{E}}$ is the Gurney energy constant; depends on the HE type ( $\mathrm{ft} / \mathrm{s})$

$\mathrm{W}$ is the weight of explosive (lbs)

$\mathrm{W}_{\mathrm{c}}$ is the case weight (lbs)

Recall that the amount of energy transferred to the cylinder wall is proportional to the ultimate strain of the shell. Consequently, the longer that a cylinder holds together during expansion, the greater the velocity of the resulting fragments. For brittle metals, the shell begins to break apart earlier, allowing the explosive gases to vent through the cracks. Thus, fragment velocity predictions for ductile metals tend to be more accurate and those for brittle metals tend to be overestimated [ 29 p.387]. Experiment has shown the Gurney formula to be fairly accurate over a range of charge-weight ratios, $W / W_{c}$, from 0.06 to 5.6. However, the theory purposely does not take into account the length of the cylinder, i.e. end effects and velocity distribution. The equation results in a single, average velocity for all fragments, regardless of location or size. It may be that the sensitivity of fragment velocity to the factors mentioned above is small and that they are indeed negligible. It is recommended that this sensitivity be determined.

While other formulas to calculate fragment velocity exist, most are severely more complex and not markedly more accurate than the Gurney equation [27]. However, Loyd gives a slightly modified 
version, equation 3, of the Gurney formula that does take into account cylinder length [3]. This modified equation seems to gives slightly better results for the data analyzed in this study.

where

$$
V_{o}=\sqrt{2 E} \sqrt{\frac{\frac{W}{W_{c}}}{\left(1+\frac{D_{e}}{2 L}\right)\left(1+\frac{W}{2 W_{c}}\right)}}
$$

$D_{e}$ is the explosive diameter (inside case diameter)

$\mathrm{L}$ is the case length

As the fragments travel through their surroundings, hydrodynamic forces act on them to slow them down. For projectile ranges of less than 20 feet (as is the case in this study) these forces are negligible, and the initial fragment velocity can be treated as equal to the striking velocity [8].

Along with velocity, it is necessary to predict fragment size. If a particular fragment geometry can be assumed, i.e. $t \times t \times t$, then calculating fragment size becomes very simple. However, it is difficult to make good assumptions about fragment dimensions. Hence, there are several models that treat fragment size.

As mentioned earlier, Grady and Hightower derived equations to predict average fragment width. Their model uses either tensile or shear fracture energy, depending on which mode of failure is assumed. In their experiment, both failure modes produced nearly equal predictions, which were very close to the measured results (see figure 9). Their equations are not very applicable to this study because they only predict average fragment widths and total number of fragments, and they require experimental parameters that are difficult to obtain. In an earlier work by Kipp and Grady, a model of fragmentation was presented in an attempt to relate strain rate to fragment size [20 p. 546-566]. A major shortcoming of this second model is that it also requires the independent experimental determination of several parameters.

Grady/Hightower

$$
S=\left(\frac{24 \Gamma}{\rho \varepsilon}\right)^{\frac{1}{3}}
$$

Kipp/Grady

$$
L_{M}=\frac{6 C_{g}}{m+2} \alpha^{\frac{-1}{m+3}} \cdot \varepsilon^{\frac{-m}{m+3}}
$$

where

$$
\begin{aligned}
& S=\text { average fragment width } \\
& \Gamma=\text { fragmentation energy }
\end{aligned}
$$




$$
\begin{aligned}
& \varepsilon^{\prime}=\text { tensile strain rate } \\
& \rho=\text { fragment density } \\
& L_{M}=\text { average fragment size } \\
& m, C_{g}, \alpha=\text { experimental parameters }
\end{aligned}
$$

Another method that is commonly used by the US military for estimating fragment size and distribution employs the Mott formula [8,12, 20 p. 547-549,28,31]. During WW II, Mott developed equations for predicting the number of fragments that are larger that a prescribed mass 9 (see equation 7). These equations can be rearranged in order to calculate average and largest-case fragments. Experiment has shown that the Mott method of analysis is quite good at predicting average fragment sizes and distributions but it loses accuracy outside of the central fragment weight range $[13,14,29]$. That is, it tends to over-predict the number and size of larger fragments and underpredict the number and size of smaller fragments. Furthermore, experimental determination of a scaling constant is required. The constant depends on a specific casing material-explosive combination. On the other hand, a major advantage of the Mott formula is that it is relatively simple and it has been widely used. Also, experimental parameters for several explosive-metal combinations have been determined. A more detailed presentation of the Mott formulae is given later.

The Navy Ordnance Laboratory attempted to modify the Mott equation and to develop three weight distribution formulas, one for each of the low, central and high weight ranges [14]. However, these formulas were derived for a specific steel type, cylinder size, and detonation point. Also, experimental parameters are given only for 24 different high explosives. Consequently, the NOL methodology is of little benefit here. Equation 5 below is for use with fragments in the high weight range.

$$
N_{f}=N_{I I I} e^{-\left(\frac{w_{f}}{\mu_{I I I}}\right)^{q}}
$$

where

$$
\begin{aligned}
& N_{f}=\text { number of fragments with weight greater than } W_{f} \\
& W_{f}=\text { design fragment weight } \\
& N_{\mathrm{III}}, \mu_{\mathrm{II}}, \mathrm{q}=\text { experimental parameters }
\end{aligned}
$$

In a report prepared in 1981 for the Naval Surface Weapons Center, numerous formulas are given (including Mott's) for predicting fragmentation characteristics of exploding bombs [28]. The report was intended to provide a comprehensive review of techniques to evaluate fragment and debris hazards. Equations are given to calculate fragment mass, number, weight, velocity, and trajectory. As is the case with nearly every model, special constants or experimental parameters are often required. Consequently, due to insufficient experimental data, it is difficult to determine whether these equations provide better predictions or not.

Sometime after Mott, Held developed a set of formulas to describe the mass distribution of fragments from HE filled cylinders [29-31]. Like the Mott equations, Held's formulas are simple and can easily be arranged to solve for the mass of the theoretical largest fragment. Similar to the models above, a 
significant disadvantage is the need for two experimental parameters that depend on shell type and geometry and the type and quantity of explosive. It appears that new parameters would need to be found for each different experiment. Due to project time constraints, the Held method was not researched completely and should be further investigated. It is given below.

where

$$
M(n)=M_{0}\left(1-e^{-B n^{\lambda}}\right)
$$

$M(n)=$ cumulative fragment mass, beginning with the largest

$\mathrm{M}_{0}=$ total mass of all fragments, i.e. mass of cylinder

$\mathrm{n}=$ cumulative fragment number, beginning with the heaviest

$\mathrm{B}, \lambda=$ experimental parameters

The Mott formula seems to provide the most viable model for predicting fragment weight. The following treatment of the Mott methodology was taken directly from reference [32].

The fragmentation pattern and the weight of the largest fragment resulting from the highorder detonation of an evenly-distributed explosive in a cylindrical metal case of uniform thickness have been calculated according to relationships developed on the basis of theoretical considerations and confirmed with a large number of tests. The number of fragments produced by a cylindrical cased charge weighing more than a given design fragment is:

$$
N_{f}=\left[8 W_{c} e^{-W_{f}^{1 / 2} / M_{A}}\right] / M_{A}^{2}
$$

and

$$
M_{A}=B_{t_{c}}^{5 / 6} d_{i}^{1 / 3}\left(1+t_{c} / d_{i}\right)
$$

where

$$
\begin{aligned}
& N_{f}=\text { number of fragments with weight greater than } W_{f} \\
& W_{c}=\text { casing weight } \\
& W_{f}=\text { design fragment weight } \\
& M_{A}=\text { fragment distribution factor } \\
& B=\text { explosive constant } \\
& t_{c}=\text { average casing thickness } \\
& d_{i}=\text { average inside diameter of casing }
\end{aligned}
$$

The largest fragment produced by an explosion can be found by setting $\mathrm{N}_{f}=1$. Thus, the weight of the largest fragment is given by:

$$
\mathrm{W}_{\mathrm{f}}=\left[\mathrm{M}_{\mathrm{A}} \ln \left(8 \mathrm{~W}_{\mathrm{c}} / \mathrm{M}_{\mathrm{A}}^{2}\right)\right]^{2}
$$

Setting the fragment weight $\mathrm{W}_{\mathrm{f}}$ equal to zero, the following expression for the total number of fragments is obtained: 


$$
\mathrm{N}_{\mathrm{T}}=8 \mathrm{~W}_{\mathrm{c}} / \mathrm{M}_{\mathrm{A}}^{2}
$$

where

$$
\mathrm{N}_{\mathrm{T}}=\text { total number of fragments }
$$

Hence, the average particle weight can be found:

$$
\mathrm{W}_{\mathrm{f}}=16 \mathrm{~W}_{\mathrm{c}} / \mathrm{N}_{\mathrm{T}}=2 \mathrm{M}_{\mathrm{A}}^{2}
$$

where

$$
\mathrm{W}_{\mathrm{f}}=\text { average fragment weight }
$$

For design purposes, a confidence level $C_{L}$, where $\left(0<C_{L}<1\right)$, can be defined as the probability that the weight, $\mathrm{W}_{\mathrm{f}}$, is the largest weight fragment released. The expression for the design fragment weight corresponding to a prescribed design confidence level $\left(\mathrm{C}_{\mathrm{L}}\right)$ is given as:

$$
C_{L}=1-N_{f} / N_{T}=1-e^{-\left[w_{f}^{1 / 2} / M_{A}\right]}
$$

or rearranging terms:

$$
\mathrm{W}_{\mathrm{f}}=\mathrm{M}_{\mathrm{A}}^{2} \ln 2\left(1-\mathrm{C}_{\mathrm{L}}\right)
$$

This equation can then be used to calculate the design fragment weight for a prescribed design confidence level. Note that the above equation uses an infinite distribution to describe a physical phenomenon which has a finite upper limit. It may be used for $C_{L} \leq 0.9999$. If $C_{L}$ $>0.9999$, use:

$$
\left.W_{f}=M_{A}^{2} \ln ^{2}\left[1-C_{L}\left(1-e^{-\left[4\left(W_{c}\right)^{1 / 2} / M_{A}\right.}\right]\right)\right]
$$

The number of fragments with weight greater than $\mathrm{W}_{\mathrm{f}}$ is:

$$
\mathrm{N}_{\mathrm{f}}=\mathrm{N}_{\mathrm{T}}\left(1-\mathrm{C}_{\mathrm{L}}\right)
$$

It should be noted that the above equations are not applicable to casings designed to fragment in a specific pattern.

It is also necessary to estimate or predict the shape and dimensions of the impacting fragments. As previously stated, the simplest case is to assume a $\mathrm{t} x \mathrm{t} \times \mathrm{t}$ shape. If a two-dimensional breakup is assumed, then the width of the fragment is merely the case thickness after it expands. This "necked down" thickness can be easily calculated according to the following:

$$
\rho_{1}=\rho_{2} \text { (assuming incompressible material) }
$$


where

$$
\rho=\text { material density }
$$

Conservation of mass then leads to

$$
A_{1}=A_{2}
$$

where

$$
A=\text { cross-sectional area }
$$

Then, putting area in terms in radius and thickness and rearranging

$$
t^{2}+2 n r_{0} t=2 r_{0} t_{0}+t_{0}^{2}
$$

where

$$
\begin{aligned}
& t=\text { expanded case thickness } \\
& \mathrm{r}_{\mathrm{b}}=\text { initial internal case radius } \\
& \mathrm{t}_{\mathrm{o}}=\text { initial case thickness } \\
& \mathrm{n}=\text { multiplication factor for expansion, i.e. } 1.5,2.0
\end{aligned}
$$

When designing for damage potential, it is sometimes useful to assume a worst-case shape and orientation, i.e. long-rod penetrator. Width and depth dimensions might be assumed to be either the initial or the expanded case thickness. The length can then be determined from the previously calculated fragment mass or simply from fitting the data. Recall that the likelihood of the largest fragment also being a long-rod penetrator is very low. A better data fit may result from dividing the maximum fragment mass prediction by the density and expanded case thickness to obtain a frontal area for the fragment. In any event, fragment geometry must be assumed or determined.

Once fragment velocity, size, and geometry have been resolved, the next step is to calculate penetration depth. There are many to choose from, each with limits of validity. Several formulas are presented in the literature [32,35-38]. Most of these equations are not pertinent to the conditions of this study. Examples include formulas by Petry, de Marre, Helié and others.

$$
\begin{array}{ll}
\text { Petry: } & P=D_{\infty}\left[1+e^{-4\left(T / D_{\infty}-2\right)}\right] \\
\text { de Marre: } & P=0.112 m_{f}^{0.33} \frac{v_{f}}{1000} \\
\text { Helié: } & P=\frac{4.608 m_{f}}{a_{1} d^{2} \pi \rho_{t}} \log _{10}\left(1+a_{2} v_{f}^{2}\right)
\end{array}
$$

where 


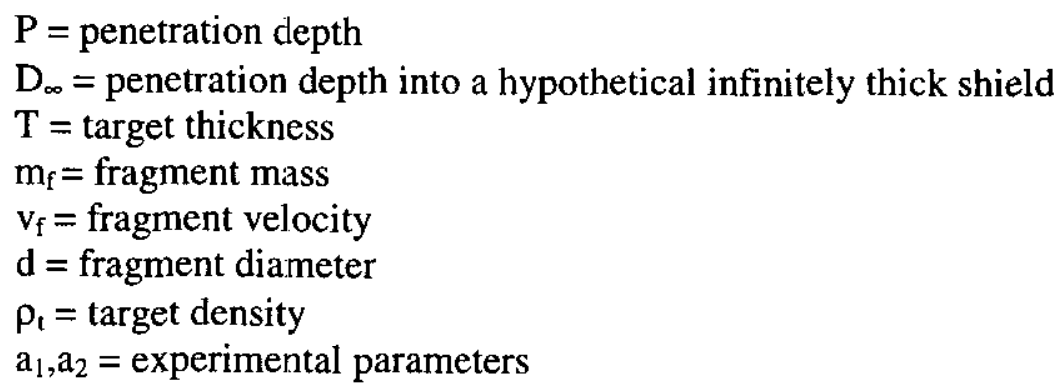

The Petry equation was originally developed for steel fragments impacting concrete or soil targets. It is restricted to very large fragments $(200-2000 \mathrm{lbs})$ and relatively low velocities $(\sim 1000 \mathrm{ft} / \mathrm{s})$. The de Marre equation is for small steel fragments between $1 / 8$ and $1 \mathrm{oz}$ impacting steel targets at velocities between $2000 \mathrm{ft} / \mathrm{s}$ and $7000 \mathrm{ft} / \mathrm{s}$. The Helie formula was developed in the mid 1800s for steel fragments and requires two experimental parameters.

Two other formulas by Thor and Christman/Gehring are more applicable and are given in detail below.

Thor:

$$
\mathrm{V}_{\mathrm{r}}=\mathrm{V}_{\mathrm{o}}-10^{\mathrm{c} 1}(\mathrm{hA})^{\alpha}\left(7000 \mathrm{~W}_{\mathrm{f}}\right)^{\beta 1}(\sec \theta)^{\gamma 1} \mathrm{~V}_{\mathrm{o}}^{\lambda 1}
$$

where

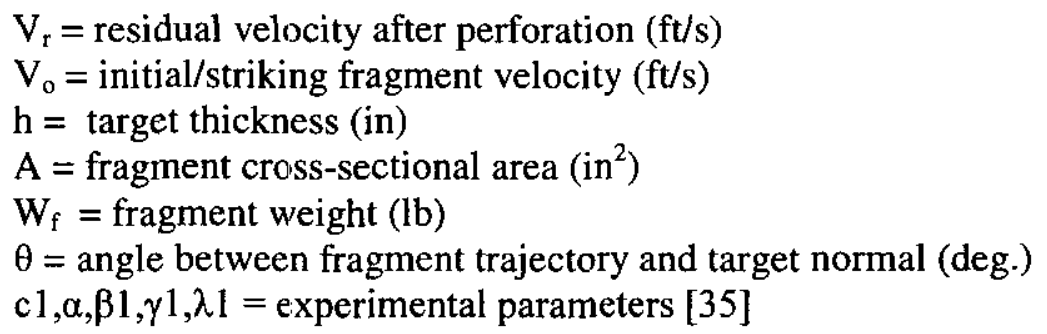

The Thor equation was developed for steel fragments impacting and perforating metal and plastic targets. The regimes of validity depend on the target material. For homogeneous steel targets, the Thor equation has limits of $600-12000 \mathrm{ft} / \mathrm{s}$ for fragment velocity and up to $1.9 \mathrm{oz}$ for fragment weight. By setting the residual velocity equal to zero and rearranging the terms, an equation for minimum target thickness $\left(\mathrm{h}_{\min }\right)$ to prevent perforation can be achieved. This can then be used to predict penetration depth. Reference [1] suggested a modification to allow for fragments other than steel.

$$
\mathrm{P}=\frac{1}{\mathrm{~A}}\left[\frac{\mathrm{V}_{\mathrm{o}}}{10^{\mathrm{c} 1}\left(7000 \mathrm{~W}_{\mathrm{f}} \rho_{\mathrm{f}} / \rho_{\mathrm{t}}\right)^{\beta 1}(\sec \theta)^{\gamma 1}}\right]^{\frac{1}{\alpha 1}}
$$

where

$$
\rho_{\mathrm{f}} / \rho_{\mathrm{t}}=\text { ratio of fragment density to target density }
$$


Two other sources give the Christman/Gehring equation for projectiles [37,38]. It is applicable to velocities between 1000 and $22,000 \mathrm{ft} / \mathrm{s}$ and is adaptable for long rods or for compact fragments of various materials.

Christman/Gehring:

$$
P=(L-D)\left(\frac{\rho_{\mathrm{f}}}{\rho_{\mathrm{t}}}\right)^{1 / 2}+0.13\left(\frac{\rho_{\mathrm{f}}}{\rho_{\mathrm{t}}}\right)^{1 / 3}\left(\frac{\mathrm{KE}}{\beta_{\max }}\right)^{1 / 3}
$$

where

$$
\begin{aligned}
& \mathrm{L}=\text { fragment length (in) } \\
& \mathrm{D}=\text { fragment diameter (in) } \\
& \rho_{\mathrm{f}} / \rho_{\mathrm{t}}=\text { ration of fragment density to target density } \\
& \mathrm{KE}=\text { fragment kinetic energy }(\mathrm{J}) \\
& \beta_{\max }=\text { maximum Brinell hardness after impact }\left(\mathrm{kg} / \mathrm{mm}^{2}\right)
\end{aligned}
$$

The first term in this equation is for the period of primary penetration, which is more important for long-rod penetrators. A similar expression appears elsewhere [24,25]. The second term is for secondary penetration, which is more important for fragments with smaller L/D ratios, i.e. compact fragments. Thus, the first term can be neglected if no long-rod penetrator is assumed.

Data Analysis

The data for this study was taken from six cylinder tests (see appendix 1). Figure 15 shows a typical experimental setup. Shrapnel was intercepted by witness plates, which were later measured for penetration depth. In several of the tests, multiple witness plates were layered together. Some fragments passed completely through one or more plates before coming to rest. Consequently, some penetration depth measurements were made by adding together the thickness of any perforated plate(s) and penetration depth in the last plate. For convenience, five of the tests are labeled with an arbitrary sample number. The sixth test is distinguishable because its was the only witness plate that was actually examined first-hand by the author. Test six is labeled LANL h-2223. An attempt was made to find the mathematical model that best represented the data. Although the amount of available information from the tests was limited, different combinations of the above mathematical models were used until the best fit was achieved. 


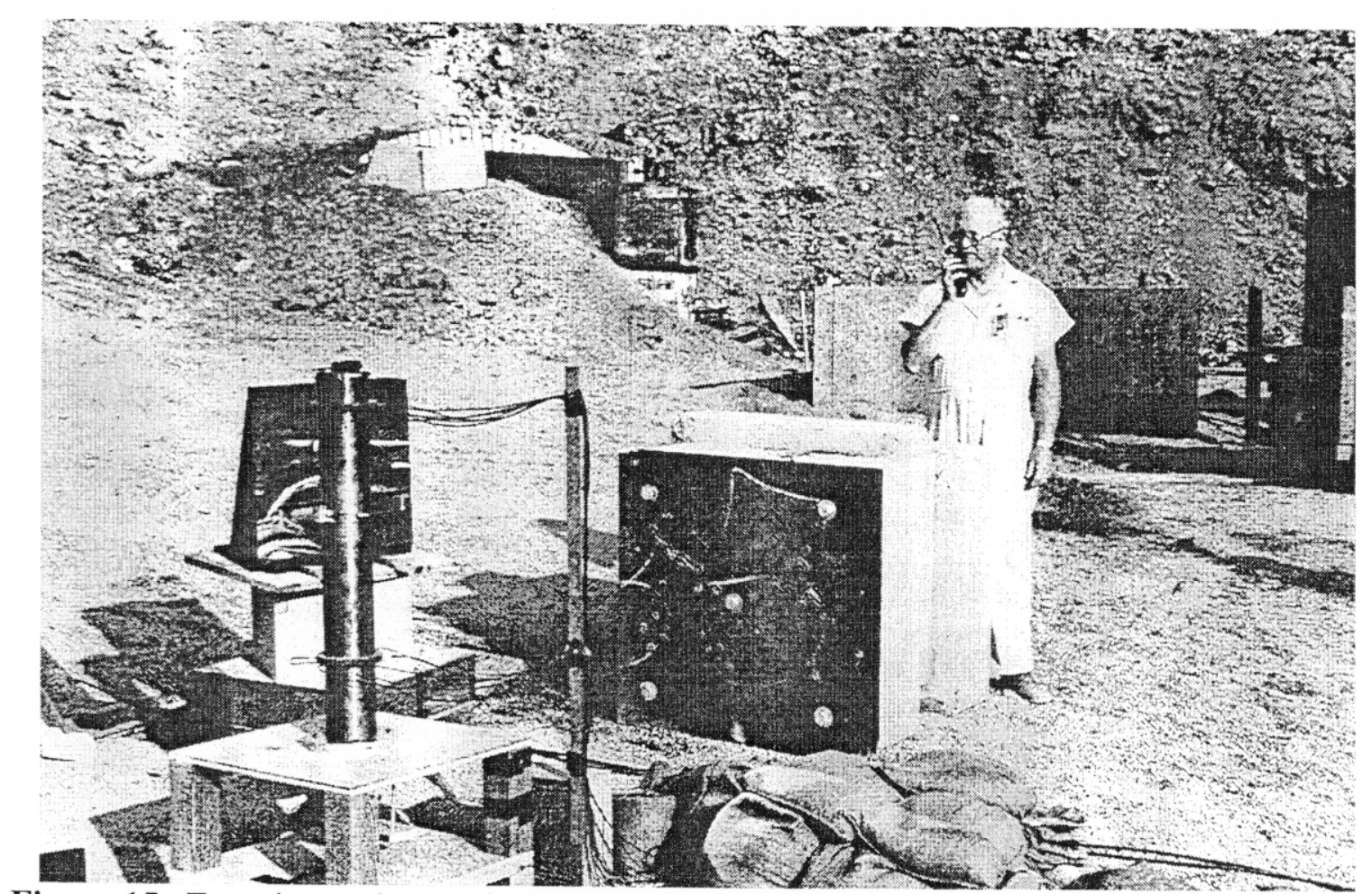

Figure 15. Experimental setup for tests 1-4 [1]. Detonation was from one end. Tests 5 and 6 were detonated a both ends of the cylinder.

It was readily determined that the modified Gurney formula (equation 2) provided the best method for calculating fragment velocity. The determination of fragment size and geometry was more difficult. Three approaches were taken. In every approach the fragment thickness was taken as the expanded case thickness and calculated according to equation 18. The Mott formula (equation 9) was used first to calculate the theoretical largest fragment weight. The frontal area of the fragment was found by dividing the weight by the fragment density and expanded case thickness. It was assumed that the fragment impacted the target with this area. A second approach for determining fragment geometry and weight was to assume a fragment size of $t \times t \times t$, where $t$ was the expanded case thickness. Frontal area and fragment weight were trivial matters. Finally, a long-rod penetrator was assumed as a third means of calculating fragment size. The height and width of the rod were taken as the expanded case thickness. The length was then back-solved from the data using equations 23 and 24 and a least-squares technique. The Mott method gave the best results.

The Thor and Christman/Gehring formulas appeared to be the most applicable penetration equations and were both compared against the data in an effort to determine which model gave a better fit. It was expected that the Christman/Gehring equation would provide better penetration predictions since it took into consideration, target and fragment densities, final target hardness (which can be related to strength), and fragment kinetic energy. Also, unlike the other formulas, the regimes of validity of this formula did not exclude any experimental conditions. Although the Christman/Gehring equation gives the best overall fit, it is interesting that the Thor equation gives the best prediction for the LANL h-2223 test. Recall that the information available from each experiment was rather limited. It must be noted that for samples 1-5 the accuracy of the penetration measurements is unknown. There may be significant error in those measurements. The LANL test provided the most reliable data. Thus, while the Christman/Gehring formula gives the best overall fit, the Thor equation should not be 
completely ruled out. Figures 16 and 17 below show the data fit. For convenience, a sample set of calculations is given in appendix 3 that follows the methodology above.

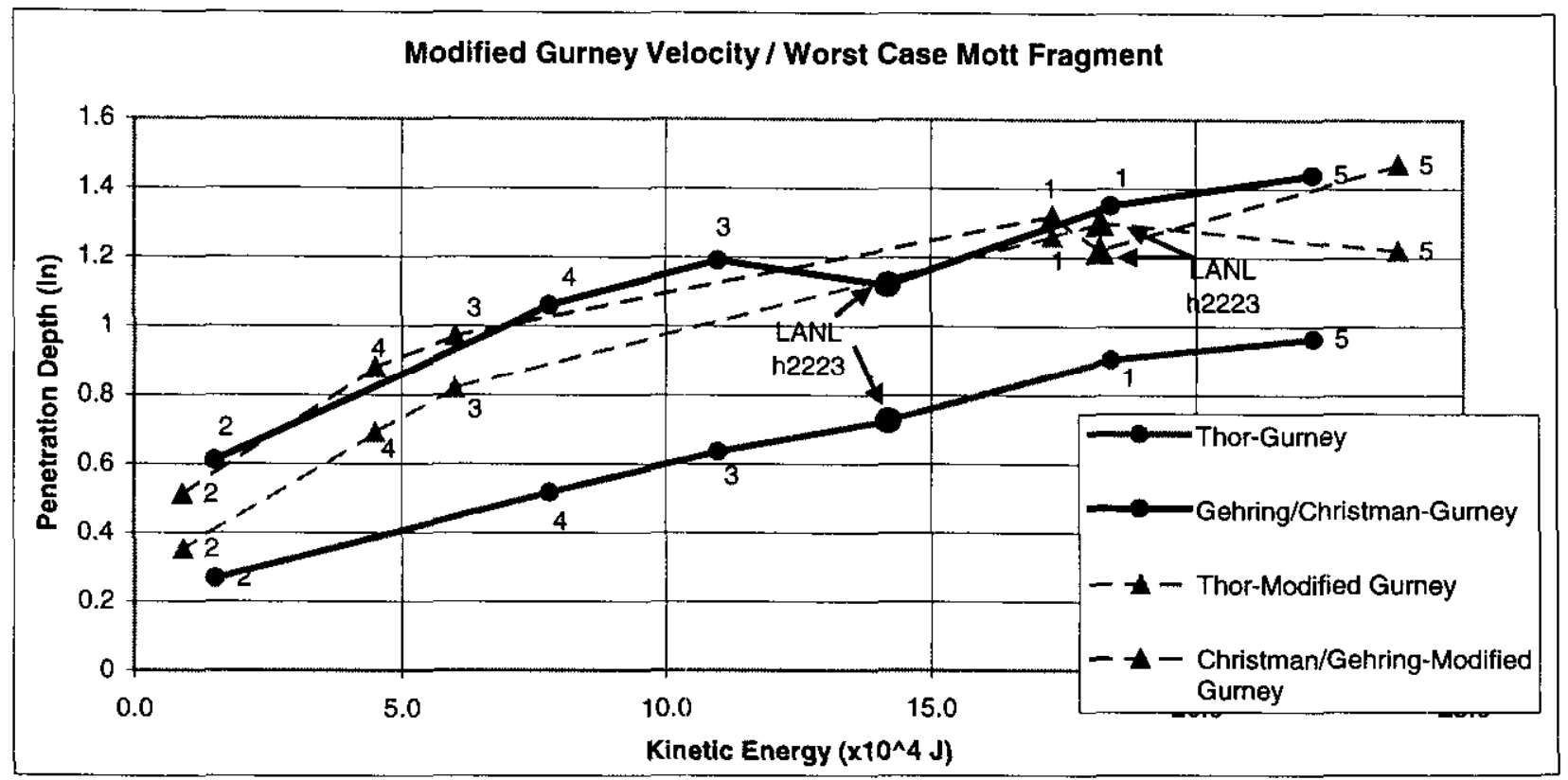

Figure 16. The Gurney, modified Gurney, and Mott formulas (equations 1, 2 and 9, respectively) were used with the experimental data. Note that the modified Gurney formula gives smoother curves. The Thor and Christman/Gehring predictions for penetration depth (equations 23 and 24, respectively) are both shown for comparison.

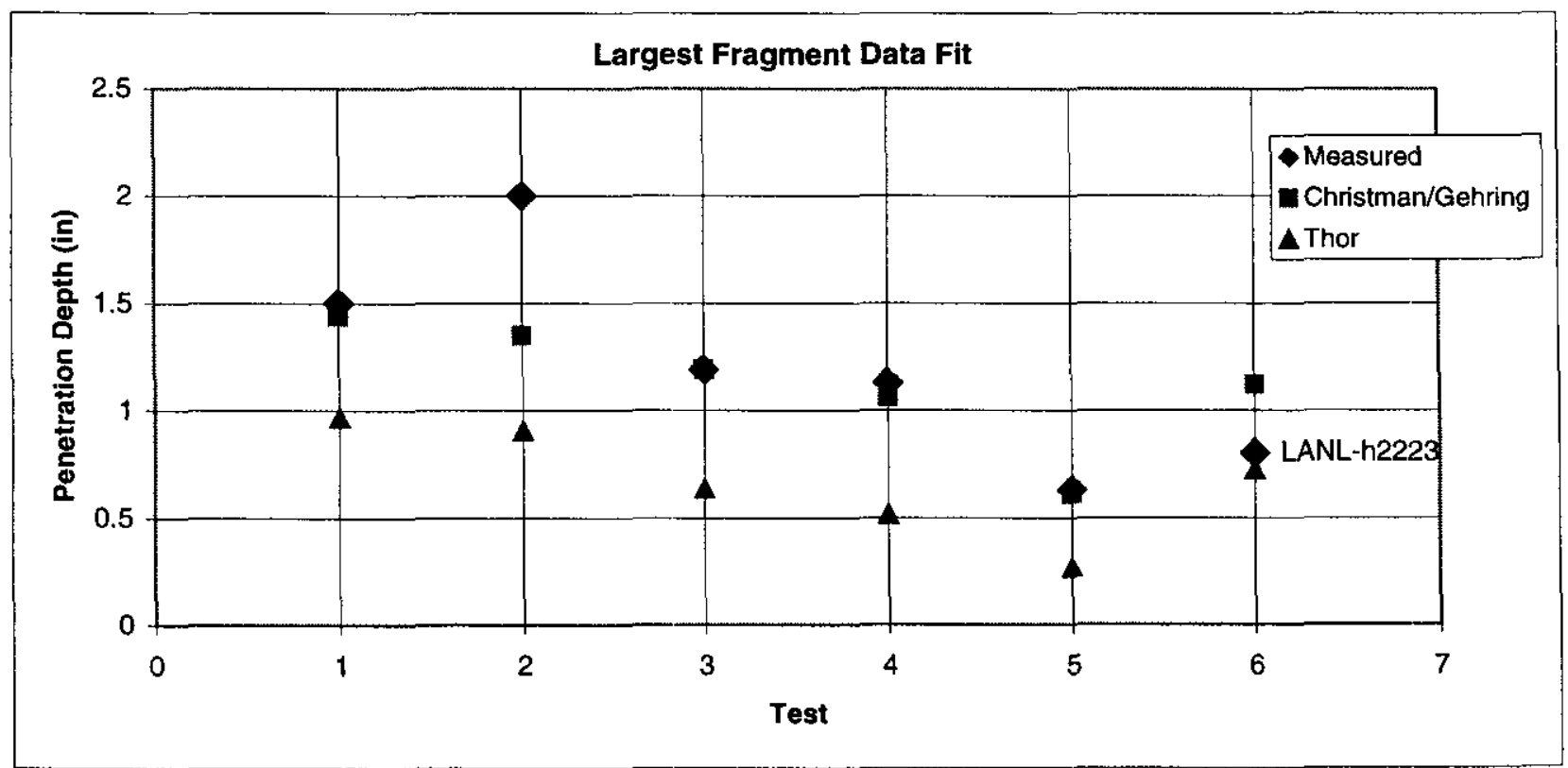

Figure 17. The measured penetration depths are compared with the predicted values. 
Recall that one of the assumptions for each of the cylinder tests was that the worst fragments would originate from the middle of the cylinders length. The witness plates were arranged in such a way to catch some of those fragments and it was assumed that the worst-case fragments were indeed sampled. One way to verify this assumption would be to collect and compare all of the fragments. Another way would be to predict and compare some of the average fragment sizes and resulting penetration depths. This was done using equations 2 and 11. From the results given in figure 18, it is clear that the largest case fragments were very likely sampled.

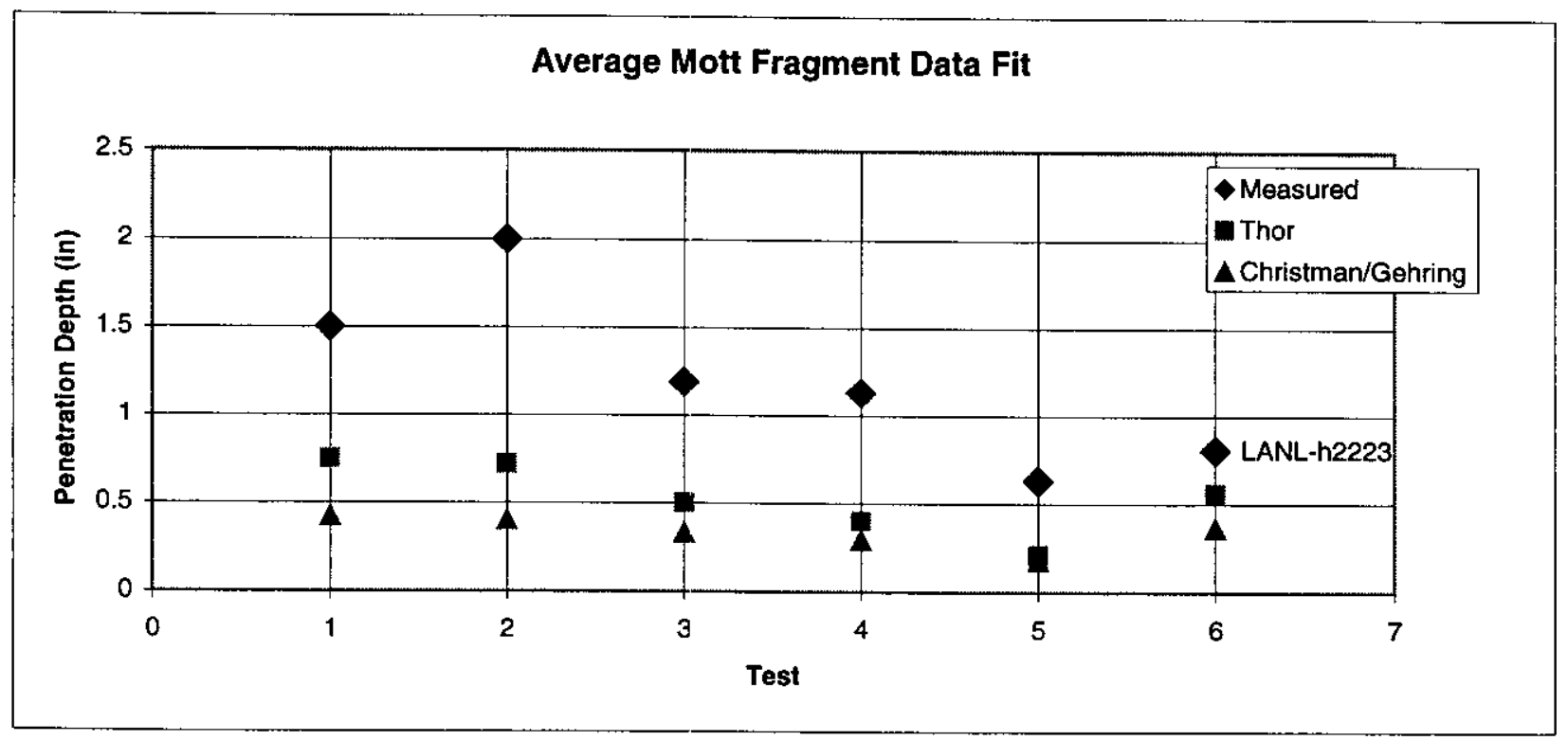

Figure 18. The test data is compared with penetration predictions based on average fragment size calculations.

The penetration depth measurements for each experiment were taken from the deepest crater in their respective witness plates. As mentioned earlier, the witness plate from the LANL test was a special case because it was examined first-hand. Consequently, it was possible to obtain penetration data from every crater, not just the deepest (see appendix 2). Data from several craters was plotted to show the crater distribution within that witness plate (see figure19). 


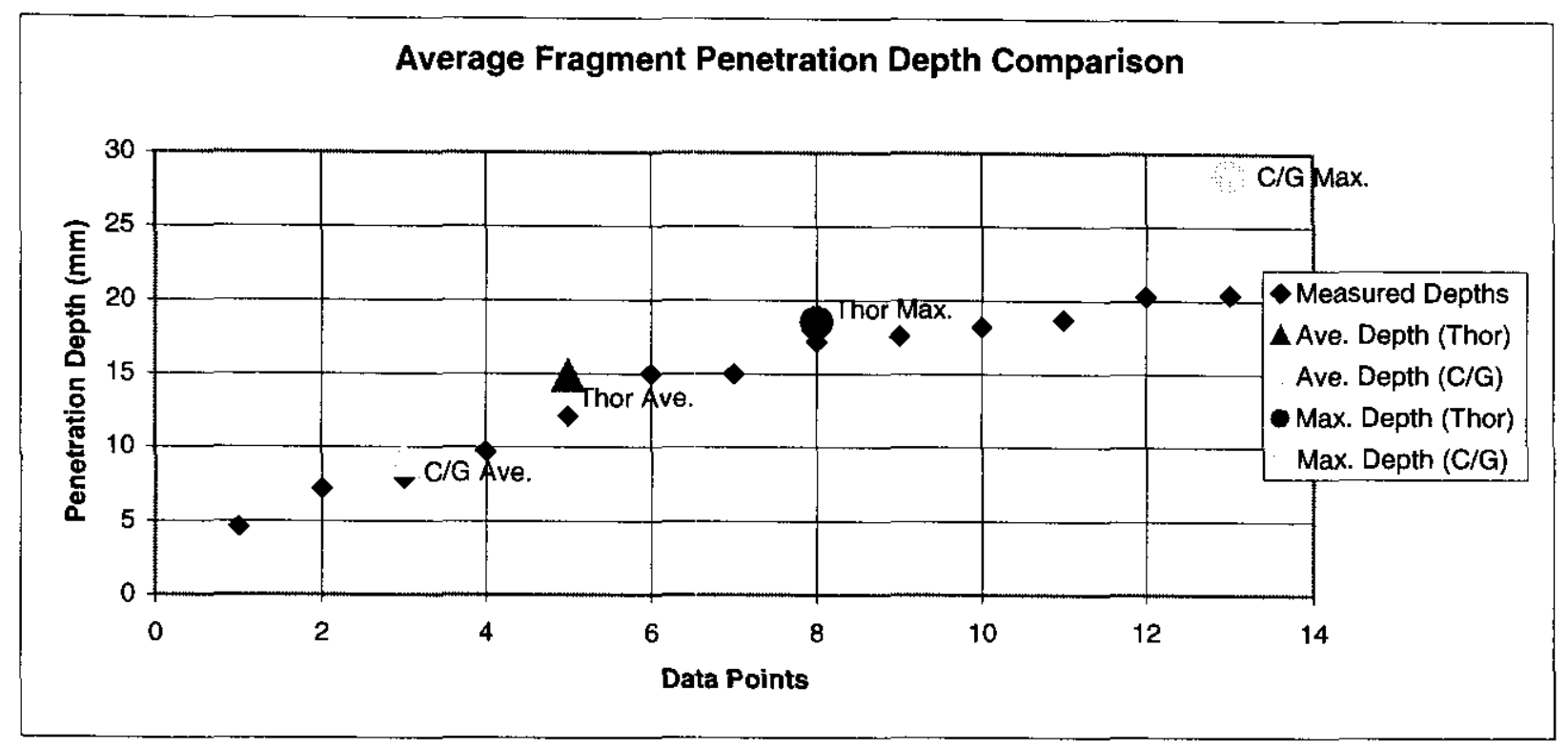

Figure 19. The crater depth distribution for the LANL h-2223 witness plate. Depth predictions are also shown for comparison. Maximum and average fragment sizes were calculated according to the Mott formulas.

There are possible sources of error in the above analysis. First, the method of measuring the penetration depths and the accuracy of those measurements was unknown for tests 1-5. Also, it was unknown whether fragments remained embedded in the target craters when the measurements were taken. Both of these unknowns may significantly affect the data fit and resulting conclusions. Furthermore, due to insufficient information, the same Mott scaling constant was used for each fragment weight calculation regardless of explosive or shell type.

\section{Conclusions and Recommendations}

Fragmentation of exploding cylinders and penetration mechanics of surrounding vessel walls were examined and a qualitative understanding was achieved. This understanding provided a basis for making simplifying approximations and assumptions that aided in creating a shrapnel penetration model. Several mathematical models were discussed, and results from 6 cylinder tests were analyzed in order to select a model that best represented the data. It was determined that the overall best mathematical model to predict shrapnel penetration uses the modified Gurney equation to calculate fragment velocity, the Mott equation to calculate largest fragment weight, and the Christman/Gehring equation to calculate penetration depth. It must be noted that these conclusions are based on the data and information available to the author at the time of the publication of this report. New data or information may partly or entirely change them.

Research for this study should not be considered complete. Due to time constraints and limited test data, there are still many questions that need to be answered. Recommendations for continued research include:

1. The Gurney formula for calculating fragment velocity gives one average velocity for all fragments. The velocity distribution of the fragments needs to be determined in order to verify the validity of this statement. 
2. It was assumed that the worst-case fragments come from the midsection of the cylinder. Although the test data suggests this is the case, this assumption should to be verified. In predicting penetration, fragment velocity is more influential than weight, and resolving the velocity distribution dilemma may solve this problem as well. It should be determined if the largest fragments also have the greatest velocity and from where they originate, which may require an actual test inside the containment vessel.

3. Fragments may have become embedded in the targets during impact. This would have resulted in incorrect penetration depth measurements, and may possibly change the best-fit model. The LANL h-2223 witness plate could be sectioned and/or tested for embedded fragments.

4. It was assumed that although elongated fragments were formed from exploding cylinders, they were oriented parallel to the target surface upon impact, i.e. no long-rod penetrators were generated. The orientation of elongated fragments upon impact should be further investigated.

5. The fragmentation models found in the literature were based on cylinders detonated at one end or at one point. It is believed that worst-case fragments come from cylinders that are detonated at both ends. Since, experiments 1-4 were detonated at one end and experiments 5 and 6 were detonated at both ends, the effect of detonating a cylinder at both ends on fragment size and velocity should be established.

6. It should be ascertained whether penetration is a kinetic energy or momentum effect. As can be seen from figure 15 , kinetic energy was used as the independent variable in this study.

7. The value of the Mott scaling constant found in equation 8 should be verified for each explosive. Since the general range of values is small, the same constant was used for each test explosive. Simple experiments may be required if the information found in literature is insufficient.

8. Due to insufficient time, it was not possible to fully research the Held formula (equation 6) for determining fragment mass. This equation may be promising and should be further investigated. 
Reference List:

1. J. W Pastrnak, C. F. Baker, and L. F. Simmons, Shrapnel Protection Testing in Support of the Proposed Site 300 Contained Firing Facility, LLNL, UCRL-ID110732. August 6, 1992.

2. P. A. Urtiew, L. M. Erickson, and T. M. Cook, Measurement of Shrapnel Velocity (1804 L Test), UCI D-21843, LLNL, November 21, 1989.

3. R. M. Loyd, ed., Conventional Warhead Systems Physics and Engineering Design, Progress in Astronautics and Aeronautics, vol. 179, American Institute of Aeronautics and Astronautics, 1998.

4. G. I. Taylor, "Analysis of the Explosion of a Long Cylindrical Bomb Detonated at One End," The Scientific Papers of Sir Geoffrey Ingram Taylor, vol. 3, no. 30, Cambridge at the University Press, 1963.

5. Personal communication with Rick Martineau from LANL on July 6, 2000.

6. D.E. Grady and M. M. Hightower, "Natural Fragmentation of Exploding Cylinders," Shock-Wave and High-Strain Rate Phenomena in Materials, edited by M. A. Meyers, L. E. Murr and K. P. Staudhammer, Marcel Dekker, Inc., New York, 1992.

7. J. Dehn, Probability Formulas for Describing Fragment Size Distributions, ARBRLTR-02332, Ballistic Research Laboratory, Aberdeen Proving Ground, Maryland, June 1981.

8. Suppressive Shield Structural Design and Analysis Handbook, HNDM-1110-1-2, 1977, section 3.7.1-2, http://www.hnd.usace.army.mil/engrdir/Publications/pubindx.htm.

9. C. R. Hoggatt and R. T. Recht," "Fracture Behavior of Tubular Bombs," Journal of Applied Physics, vol. 39, no. 3, 1968.

10. G. I Taylor, "The Fragmentation of Tubular Bombs," The Scientific Papers of Sir Geoffrey Ingram Taylor, vol. 3, no. 44, Cambridge at the University Press, 1963.

11. R. L Martineau, A Viscoplastic Model of Expanding Cylindrical Shells Subjected to Internal Explosive Detonations, LANL, LA-13424-T or UC-741, April 1998.

12. N. F. Mott, "Fragmentation of shell cases", Proc. Royal Soc. London, vol. 189.

13. Personal communication with Edward Rodriguez at LANL, June 6, 2000.

14. H. M. Sternberg, "Fragment Weight Distributions from Naturally Fragmenting Cylinders Loaded with Various Explosives," NOLTR-73-83, Naval Ordnance Laboratory, White Oak, Silver Spring, MD, October 1973.

15. P. W. Cooper and S. R. Kurowski, Introduction to the Technology of Explosives, Wiley-VCH, New York, 1996, 80.

16. Hallock F. Swift, "Hypervelocity Impact Mechanics," Impact Dynamics, co-authors J. A. Zukas, T. Nicholas, H. F. Swift, L. B. Greszczuk and D. R. Curran, John Wiley \& Sons, New York, 1982.

17. Los Alamos witness plate.

18. J. A. Zukas, "Numerical Simulation of High Rate Behavior," Shock and Impact on Structures, editors C. A. Brebbia and V. Sanchez-Galvez, Computational Mechanics Publications, Boston, 1994, 1-26.

19. Jonas A. Zukas, "Penetration and Perforation of Solids," Impact Dynamics, coauthors J. A. Zukas, T. Nicholas, H. F. Swift, L. B. Greszczuk and D. R. Curran, John Wiley \& Sons, New York, 1982.

20. M. A. Meyers, Dynamic Behavior of Materials, John Wiley \& Sons, Inc.

21. R. F. Recht and T. W. Ipson, "Ballistic Perforation Dynamics," Transaction on the ASME Journal, September 1973, 388-389. 
22. S. R. Bodner, "Modelling Ballistic Perforation," Structural Impact and Crashworthiness, vol. 1, edited by G. A. O. Davies, Elsevier Applied Science Publishers, New York, 1984.

23. R. L. Woodward, "Modelling Geometrical and Dimensional Aspects of Ballistic Penetration of Thick Metal Targets." International Journal of Impact Engineering, 1996, 369-381.

24. A. Gunnar Wijk, "High-velocity Projectile Penetration into Thick Armour Targets," International Journal of Impact Engineering, 1999, 45-54.

25. S. J. Bless, J. P. Barber, R. S. Bertke and H. F. Swift, "Penetration Mechanics of Yawed Rods," International Journal of Engineering Science, vol. 16 (1978), 829834.

26. T. Bervik, M. Langseth, O. S. Hopperstad, K. A. Malo, "Ballistic Penetration of Steel Plates, International Journal of Impact Engineering, 1999, 855-886.

27. Irvin G. Henry, The Gurney Formula and Related Approximations for the HighExplosive Deployment of Fragments, report no. PUB-189, Aerospace Group, Hughes Aircraft Company, Culver City, CA, 1967.

28. J. C. Hokanson, L. M. Vargas, M. G. Whitney, P. K. Moseley, and J. W. Cardinal, Fragment and Debris Hazards from Accidental Explosions, NSWC TR 85-114, Naval Surface Weapons Center, Dahlgren, Virginia, 1981.

29. M. Held, "Consideration of the Mass Distribution of Fragments by Natural Fragmentation in Combination with Preformed Fragments," Propellants and Explosives, vol. 1, 1976.

30. M. Held, "Fragment Mass Distribution of HE Projectiles," Propellants, Explosives, Pyrotechnics, vol. 15, 1990.

31. J. Carleone, ed., "Tactical Missile Warheads", Progress in Astronautics and Aeronautics, vol. 155, American Institute of Aeronautics and Astronautics (AIAA), 1993, chapter 8.

32. Structures to Resist the Accidental Effects of Explosions, TM5-1300/NAVFAC P397/AFR 88-22, 1990.

33. P. W. Cooper, Explosives Engineering, Wiley-VCH, New York, 1996.

34. R. W. Gurney, The Initial Velocities of Fragments from Bombs, Shell, and Grenades, BRL report no. 405, Ballistic Research Laboratory, Aberdeen Proving Ground, Maryland, September 1943.

35. Design Safety Standards, Lawrence Livermore National Laboratory, 1995, part IV.

36. M. J. Forrestal, A. S. Brar, and V. K. Luk, "Penetration of Strain-hardening Targets with Rigid Spherical-nose Rods," Computational Techniques for Contact, Impact, Penetration, and Perforation of Solids, edited by L. E. Schwer. N. J. Salamon, and W. K. Liu, 1989.

37. D. R. Christman and J. W. Gehring, "Analysis of High Velocity Projectile Penetration Mechanics," Journal of Applied Physics, vol. 37 no. 4, March 15, 1960.

38. M. E. Backman and W. Goldsmith, "The Mechanics of Penetration of Projectile into Targets," International Journal of Engineering Science, vol. 16, 1978, 1-99. 


\section{Appendix I}

\section{Test Data for 6 Cylinder Tests}

Fragment

\begin{tabular}{|r|l|r|r|r|r|r|r|}
\hline Experiment $^{*}$ & Material & $\begin{array}{r}\text { Weight Density } \\
\text { (lbs/in^3) }\end{array}$ & $\begin{array}{l}\text { Initial Case } \\
\text { Thickness (in) }\end{array}$ & $\begin{array}{l}\text { Expansion } \\
(\%)\end{array}$ & $\begin{array}{l}\text { Expanded case } \\
\text { thickness (in) }\end{array}$ & $\begin{array}{l}\text { Case } \\
\text { length } \\
\text { (in) }\end{array}$ & $\begin{array}{l}\text { Case ID } \\
\text { (in) }\end{array}$ \\
\hline 1 & Steel & 0.283 & 0.5 & 140 & 0.3624 & 17 & 8.0 \\
\hline 2 Copper & 0.323 & 0.2 & 200 & 0.1009 & 12 & 2.0 \\
\hline 3 Copper & 0.323 & 0.4 & 210 & 0.1941 & 40 & 4.0 \\
\hline 4 & Copper & 0.323 & 0.4 & 210 & 0.1941 & 48 & 4.0 \\
\hline 5 & Steel & 0.283 & 0.375 & 130 & 0.2911 & 13.25 & 10.0 \\
\hline LANL h-2223 & Steel & 0.283 & 0.5 & 140 & 0.3624 & 6 & 8 \\
\hline
\end{tabular}

*Information for experiments $1-5$ was obtained from reference [1] and correspond to test no.'s $2,3,4,7$, and 9 , respectively, as labeled therein. The sixth experiment was conducted at Los Alamos National Laboratory and is denoted by its shot number. Note that tests 1-4 were detonated at one end of the cylinder and tests 5 and 6 were detonated at both ends.

**The thinning of the initial case thickness, due to cylinder expansion, is taken into account. It was assumed that steel cylinders expand $120-150 \%$ and copper cylinders expand $200-220 \%$, depending on initial case thickness. Varying the expansion percentage by 20 only changed the Thor predictions by about 0.1 in. Adjusting the expanded case thickness only affects the worst-case Thor and long rod-penetrator predictions.

HE

\begin{tabular}{|r|r|r|r|l|}
\hline & & & & \\
Experiment & Material & Amount (lbs) & $\begin{array}{l}\text { Gurney } \\
\text { Constant (t/s) }\end{array}$ & $\begin{array}{l}\text { Mott Explosive } \\
\text { Constant }\end{array}$ \\
\hline 1 & $\mathrm{RX}-35-\mathrm{BT}$ & 41 & 8068 & 0.22 \\
\hline 2 & $\mathrm{RX}-35-\mathrm{BT}$ & 2.5 & 8068 & 0.22 \\
\hline 3 & $\mathrm{RX}-35-\mathrm{BT}$ & 40 & 8068 & 0.22 \\
\hline 4 & Lovex & 30 & 8068 & 0.22 \\
\hline 5 & $\mathrm{C4}$ & 60 & 8800 & 0.22 \\
\hline LANL h-2223 & PBX-9501 & 13.73 & 9514 & 0.22 \\
\hline
\end{tabular}

Target

\begin{tabular}{|c|c|c|c|c|c|}
\hline Experiment & Material & $\begin{array}{l}\text { Weight Density } \\
\text { (lbs/in^3) }\end{array}$ & $\begin{array}{l}\text { Max. HB } \\
\left(\mathrm{kg} / \mathrm{mm}^{\wedge} 2\right)\end{array}$ & $\begin{array}{l}\text { Penetration + } \\
\text { Perforation (in) }\end{array}$ & $\begin{array}{l}\text { Measured } \\
\text { Depth (in) }\end{array}$ \\
\hline 1 & A36 & 0.283 & 165 & $0.5+1.5$ & 2.00 \\
\hline 2 & A36 & 0.283 & 165 & $0.5+0.125$ & 0.63 \\
\hline 3 & A36 & 0.283 & 165 & $0.5+0.5+0.1875$ & 1.19 \\
\hline 4 & A36 & 0.283 & 165 & $1+0.125$ & 1.13 \\
\hline 5 & 1008 & 0.283 & 165 & 1.5 & 1.50 \\
\hline LANL h-2223 & HSLA 100 & 0.283 & 220 & 0.803 & 0.803 \\
\hline
\end{tabular}

LANL h-2223 experiment provided the most reliable prediction and results comparison. 


\section{Appendix 2}

\section{Test Data for Witness Plate form LANL h-2223 Test}

Experiment Shrapnel 2" $\times 12^{\prime \prime} \times 12^{\prime \prime}$ HSLA 100

\begin{tabular}{|c|c|c|c|c|}
\hline HIT \# & SIZE $(x, y) \mathrm{mm}$ & $\begin{array}{c}\text { LOCATION }+/- \\
2 \mathrm{~mm}(x, y) \mathrm{mm}\end{array}$ & DEPTH mm & VOLUME cc \\
\hline 1 & 42,47 & 51,76 & 20.3 & 8.4 \\
\hline 2 & 61,45 & 76,81 & 18.2 & 9.9 \\
\hline 3 & 38,28 & 132,66 & 7.2 & 1.5 \\
\hline 4 & 32,42 & 160,79 & 18.7 & 6.2 \\
\hline 5 & 26,45 & 191,66 & 12.1 & 10.2 \\
\hline 6 & 48,54 & 246,76 & 17.2 & 12 \\
\hline 7 & 30,22 & 15,175 & 20.4 & 4.1 \\
\hline 8 & 74,67 & 69,173 & 15 & 14.5 \\
\hline 9 & 53,51 & 178,173 & 17.6 & 13.2 \\
\hline 10 & 54,60 & 264,170 & 15 & 10.5 \\
\hline 11 & 23,27 & 130,272 & 7.9 & 1.6 \\
\hline 12 & 26,34 & 193,287 & 4.6 & 1.3 \\
\hline 13 & 32,24 & 244,287 & 9.7 & 3 \\
\hline
\end{tabular}

\section{Notes}

1. Upper left comer of $305 \mathrm{~mm} \times 305 \mathrm{~mm} \times 51 \mathrm{~mm}$ " HSLA 100 plate is 0,0 origin.

2. Front face of $2^{n}$ plate is depth and volume origin.

3. Size dimensions are the max. in both $x$ and $y$.

4. Location dimensions are estimated center of shrapnel hits in both $x$ and $y$.

5. Depth is the deepest shrapnel hit measured.

6. Volume was checked with water up to original plate surface.

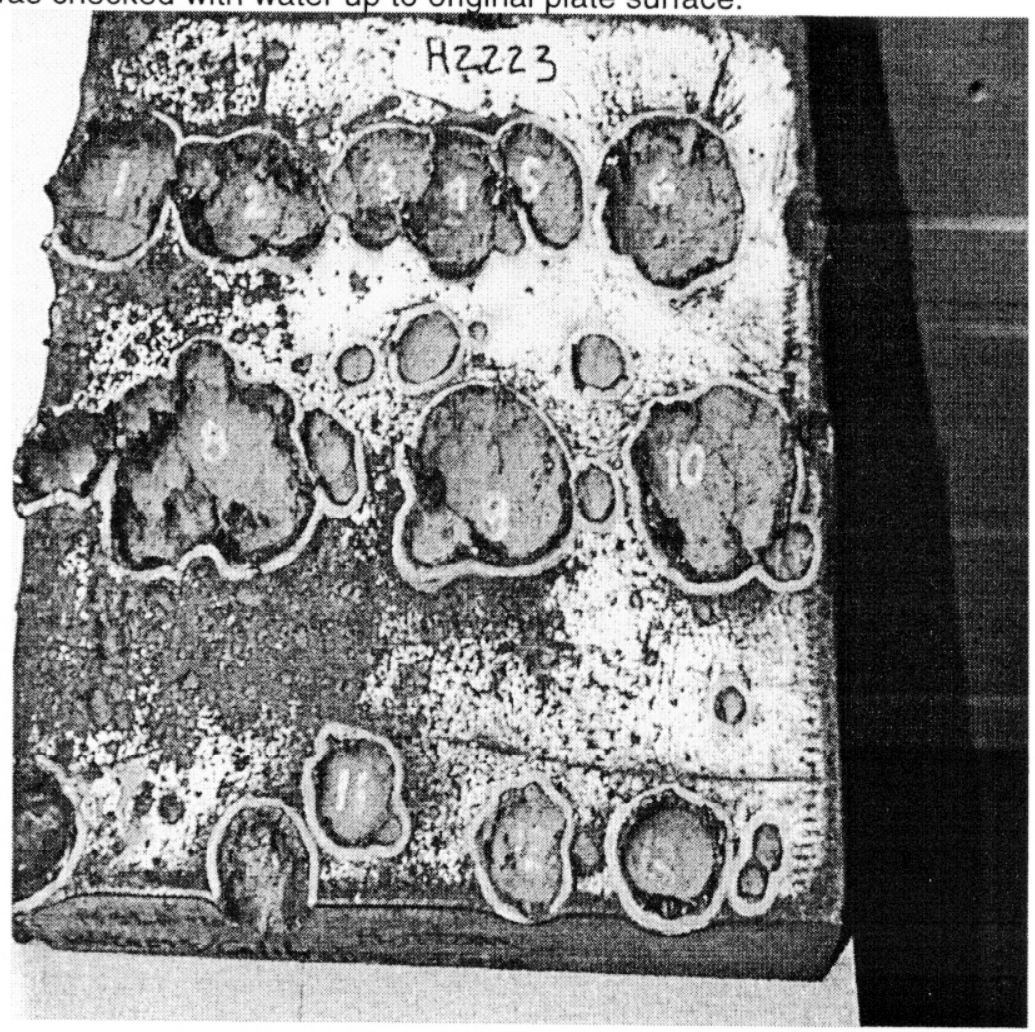




\section{Appendix 3}

\section{Sample set of Calculations}

These calculations follow the methodology described in data analysis section. The data used is from the LANL h-2223 experiment.

1. Calculate the case weight according to

$$
\mathrm{W}_{\mathrm{c}}=\gamma_{\mathrm{f}} \frac{\pi}{4}\left[\left(\mathrm{ID}+2 \mathrm{t}_{\mathrm{o}}\right)^{2}-\mathrm{ID}^{2}\right]
$$

where

$$
\begin{aligned}
& \gamma_{\mathrm{f}}=\text { case weight density } \\
& \text { ID }=\text { initial inside diameter } \\
& t_{\mathrm{o}}=\text { initial case thickness } \\
& \mathrm{L}=\text { case length }
\end{aligned}
$$

$$
\mathrm{W}_{\mathrm{c}}=\left(0.283 \frac{\mathrm{lbs}}{\mathrm{in}^{3}}\right)\left(\frac{\pi}{4}\right)\left[(8.0 \mathrm{in}+2(0.5 \mathrm{in}))^{2}-(8.0 \mathrm{in})^{2}\right](6.0 \mathrm{in})=\mathbf{2 2 . 6 7 l b s}
$$

2. Calculate the fragment velocity using equation 2 .

$$
V_{o}=\sqrt{2 E} \sqrt{\frac{\frac{W}{W_{c}}}{\left(1+\frac{D_{e}}{2 L}\right)\left(1+\frac{W}{2 W_{c}}\right)}}
$$

where $\quad \mathrm{V}_{0}=$ initial velocity of the case fragment (f/s)

$$
\begin{aligned}
& (2 \mathrm{E})^{1 / 2}=\text { Gurney energy constant; depends on the HE type (f/s) } \\
& W=\text { weight of explosive (lbs) } \\
& W_{c}=\text { case weight (lbs) } \\
& D_{e}=\text { explosive diameter (inside case diameter) }
\end{aligned}
$$

$$
\mathrm{V}_{\mathrm{o}}=\left(9514 \frac{\mathrm{ft}}{\mathrm{s}}\right) \sqrt{\frac{\frac{13.73 \mathrm{lbs}}{22.67 \mathrm{lbs}}}{\left(1+\frac{8.0 \mathrm{in}}{2 * 6.0 \mathrm{in}}\right)\left(1+\frac{13.731 \mathrm{bs}}{2 * 22.67 \mathrm{lbs}}\right)}}=\mathbf{5 0 2 4 . 6 \frac { \mathrm { ft } } { \mathrm { s } }}
$$

3. Calculate the largest fragment weight using equations 7 and 8 .

$$
\begin{aligned}
& \mathrm{M}_{\mathrm{A}}=\mathrm{Bt}_{\mathrm{c}}^{5 / 6} \mathrm{~d}_{\mathrm{i}}^{1 / 3}\left(1+\mathrm{t}_{\mathrm{c}} / \mathrm{d}_{\mathrm{i}}\right) \\
& \mathrm{W}_{\mathrm{f}}=\left[\mathrm{M}_{\mathrm{A}} \ln \left(8 \mathrm{~W}_{\mathrm{c}} / \mathrm{M}_{\mathrm{A}}^{2}\right)\right]^{2}
\end{aligned}
$$

where

$\mathrm{W}_{\mathrm{c}}=$ casing weight (lbs)

$\mathrm{W}_{\mathrm{f}}=$ design fragment weight $(\mathrm{oz})$

$M_{A}=$ fragment distribution factor

$\mathrm{B}=$ explosive constant 


$$
\begin{aligned}
& t_{c}=\text { casing thickness } \\
& d_{i}=\text { inside diameter of casing }
\end{aligned}
$$

$\mathrm{M}_{\mathrm{A}}=(0.22)(0.5 \mathrm{in})^{5 / 6}(8.0 \mathrm{in})^{1 / 3}(1+0.5 \mathrm{in} / 8.0 \mathrm{in})=0.26238$

$\mathrm{W}_{\mathrm{f}}=\left[(0.26238) \ln \left(8 * 22.67 \mathrm{lbs} /(0.26238)^{2}\right)\right]^{2}=4.27 \mathrm{oz}$

4. Calculate penetration depth (Thor) using equation 23 .

$$
\mathrm{P}=\frac{1}{\mathrm{~A}}\left[\frac{\mathrm{V}_{\mathrm{o}}}{10^{\mathrm{cl}}\left(7000 \mathrm{~W}_{\mathrm{f}} \rho_{\mathrm{f}} / \rho_{\mathrm{t}}\right)^{\beta 1}(\sec \theta)^{\gamma 1}}\right]^{\frac{1}{\alpha 1}}
$$

where

$$
\begin{aligned}
& V_{o}=\text { initial/striking fragment velocity }(\mathrm{ft} / \mathrm{s}) \\
& \mathrm{P}=\text { penetration depth (in) } \\
& \mathrm{A}=\text { fragment cross-sectional area }\left(\mathrm{in}^{2}\right) \\
& \mathrm{W}_{\mathrm{f}}=\text { fragment weight }(\mathrm{lb}) \\
& \theta=\text { angle between fragment trajectory and target normal (deg.) } \\
& \mathrm{cl}, \alpha, \beta 1, \gamma 1, \lambda 1=\text { experimental parameters [32] } \\
& \rho_{\mathrm{f}} / \rho_{\mathrm{t}}=\text { ratio of fragment density to target density }
\end{aligned}
$$

and

$A=W_{f} /\left(\rho_{f} t\right)$

where

$$
\mathrm{t}=\text { expanded case thickness found according to equation } 18 \text { using an }
$$
expansion factor of 1.4 .

$\mathrm{A}=(4.27 \mathrm{oz})(1 \mathrm{lb} / 16 \mathrm{oz}) /\left[\left(0.283 \mathrm{lb} / \mathrm{in}^{3}\right)(0.3624 \mathrm{in})=2.602 \mathrm{in}^{2}\right.$

$$
\mathrm{P}=\frac{1}{2.602 \mathrm{in}^{2}}\left[\frac{5024.6 \frac{\mathrm{ft}}{\mathrm{s}}}{10^{6.601}\left(7000(4.72 \mathrm{oz})\left(\frac{1 \mathrm{lb}}{16 \mathrm{oz}}\right)(0.283 / 0.283)\right)^{-0.963}(\mathrm{sec} 0)^{1.286}}\right]^{\frac{1}{0.906}}=\mathbf{0 . 7 2 3 i n}
$$

5. Calculate penetration depth (Christman/Gehring) using equation 24 . Remember that since the fragment is not a long-rod penetrator, the first term can be neglected.

$$
\mathrm{P}=0.13\left(\frac{\rho_{\mathrm{f}}}{\rho_{\mathrm{t}}}\right)^{1 / 3}\left(\frac{\mathrm{KE}}{\beta_{\max }}\right)^{1 / 3}
$$

where

$$
\begin{aligned}
& \mathrm{L}=\text { fragment length (in) } \\
& \mathrm{D}=\text { fragment diameter (in) }
\end{aligned}
$$




$$
\begin{gathered}
\rho_{\mathrm{f}} / \rho_{\mathrm{t}}=\text { ration of fragment density to target density } \\
\mathrm{KE}=\text { fragment kinetic energy }(\mathrm{J}) \\
\beta_{\max }=\text { maximum Brinell hardness after impact }\left(\mathrm{kg} / \mathrm{mm}^{2}\right) \\
\mathrm{KE}=\frac{1}{2} \mathrm{~m}_{\mathrm{f}} \mathrm{V}_{\mathrm{o}}^{2}=\frac{1}{2}(4.27 \mathrm{oz})\left(\frac{1 \mathrm{lb}}{16 \mathrm{oz}}\right)\left(\frac{0.454 \mathrm{~kg}}{1 \mathrm{lb}}\right)\left[\left(5024.6 \frac{\mathrm{ft}}{\mathrm{s}}\right)\left(\frac{1 \mathrm{~m}}{3.28 \mathrm{ft}}\right)\right]^{2}=14.22 \times 10^{4} \mathrm{~J} \\
\mathrm{P}=0.13\left(\frac{0.283}{0.283}\right)^{1 / 3}\left(\frac{14.22 \times 10^{4} \mathrm{~J}}{220 \frac{\mathrm{kg}}{\mathrm{mm}^{2}}}\right)^{1 / 3}=\mathbf{1 . 1 2 \mathrm { in }}
\end{gathered}
$$

